\title{
Diabetes mellitus: new challenges and innovative therapies
}

\author{
Cristina M. Sena $\cdot$ Carla F. Bento $\cdot$ Paulo Pereira • \\ Raquel Seiça
}

Received: 16 December 2009/Accepted: 4 February 2010/Published online: 13 March 2010

(C) European Association for Predictive, Preventive and Personalised Medicine 2010

\begin{abstract}
Diabetes mellitus is a widespread disease prevalence and incidence of which increases worldwide. The introduction of insulin therapy represented a major breakthrough in type 1 diabetes; however, frequent hyper- and hypoglycemia seriously affects the quality of life of these patients. New therapeutic approaches, such as whole pancreas transplant or pancreatic islet transplant, stem cell, gene therapy and islets encapsulation are discussed in this review. Regarding type 2 diabetes, therapy has been based on drugs that stimulate insulin secretion (sulphonylureas and rapid-acting secretagogues), reduce hepatic glucose production (biguanides), delay digestion and absorption of intestinal carbohydrate (alpha-glucosidase inhibitors) or improve insulin action (thiazolidinediones). This review is also focused on the newer therapeutically approaches such as incretin-based therapies, bariatric surgery, stem cells and other emerging therapies that promise to further extend the options available. Gene-based therapies are among the most promising emerging alternatives to conventional treatments. Some of these therapies rely on genetic modification of
\end{abstract}

C. M. Sena $(\bowtie) \cdot$ R. Seiça

Institute of Physiology, Faculty of Medicine,

University of Coimbra,

Subunit 1, polo 3, Azinhaga de Santa Comba, Celas,

3000-354 Coimbra, Portugal

e-mail: csena@ci.uc.pt

C. M. Sena • C. F. Bento • P. Pereira • R. Seiça

IBILI, University of Coimbra,

Coimbra, Portugal

C. F. Bento $\cdot$ P. Pereira

Centre of Ophthalmology, Faculty of Medicine,

University of Coimbra,

Coimbra, Portugal non-differentiated cells to express pancreatic endocrine developmental factors, promoting differentiation of nonendocrine cells into $\beta$-cells, enabling synthesis and secretion of insulin in a glucose-regulated manner. Alternative therapies based on gene silencing using vector systems to deliver interference RNA to cells (i.e. against VEGF in diabetic retinopathy) are also a promising therapeutic option for the treatment of several diabetic complications. In conclusion, treatment of diabetes faces now a new era that is characterized by a variety of innovative therapeutic approaches that will improve quality-life and allow personalized therapyplanning in the near future.

Keywords Diabetes mellitus - New therapeutic approaches . Incretin-based therapies · Bariatric surgery · Gene-based therapies

\section{Introduction}

Diabetes mellitus is increasing globally affecting more than 180 million people worldwide [1]. This is mostly type 2 diabetes and, because of the increase in the aging population and massive rise in prevalence of obesity, the incidence is likely to be more than doubled by $2030[1,2]$. Diabetes is a global problem with devastating human, social and economic impact. A major concern with the diabetes epidemic is the anticipated increase in mortality and morbidity related to the complications of the disease [3, 4]. Insufficient drug therapies, poor patient compliance to therapy and inadequate management regimes may be contribute to the increasing incidence of complications linked to the disease. 


\section{Glycemic control}

Glycemic control is fundamental to the management of diabetes. It is now established that the risk of diabetic complications is dependent on the degree of glycemic control in diabetic patients. Clinical trials such as the Diabetes Control and Complications Trial [5] and the Stockholm Diabetes Study in type 1 diabetes [6], and the UK Prospective Diabetes study [7, 8] and Kumamoto study [9] in type 2 diabetes, have demonstrated that tight glycemic control achieved with intensive insulin regimes can reduce the risk of developing or progressing retinopathy, nephropathy and neuropathy in patients with all types of diabetes. However, the Third National Health and Nutrition Examination Survey (NHANES III) showed that only $50 \%$ of diabetics have been able to achieve a glycosylated hemoglobin (HbA1C) level, as an index of chronic glycemia, less than 7\%; therefore, the only way to ensure the long-term health of diabetic patients is to maintain constant normoglycaemia [2].

The goal of antidiabetes therapy is to reduce hyperglycemia to either prevent or minimize the complications associated with this disease. HbA1C levels are a measure of glycemic control, and antidiabetes treatment aims to reduce $\mathrm{HbA1C}$ to as close to normal $(<6.0 \%)$ as possible, without inducing hypoglycemia. Improved glycemic control is associated with significant reductions in microvascular complications, such as retinopathy, nephropathy, and neuropathy $[7,8]$. In a metaanalysis, tight glycemic control has also been shown to reduce cardiovascular disease [10]. As a result, a clinical trial is currently investigating whether reducing $\mathrm{HbAlC}$ to less than $6.0 \%$ decreases the rate of cardiovascular disease and death [11, 12], which would be clinically beneficial as macrovascular disease accounts for approximately $50 \%$ of deaths in individuals with type 2 diabetes.

In type 2 diabetes, despite the clinical benefits of tight glycemic control and the availability of many distinct antidiabetic agents, treatments tend to become less effective over time as insulin resistance increases and pancreatic $\beta$ cell function deteriorates. Patients with type 1 diabetes are unable to maintain normoglycemia at all times, even with an intensive insulin therapy.

Insight into the pathophysiology of diabetes and its complications has led to the development of improved therapeutic strategies. Proper glycemic control and attainment of other nonglycemic management targets (e.g., blood pressure, lipids, body weight) are essential to the prevention of long-term complications of diabetes and to the reduction of overall disease management costs. Two prime examples of such therapy are treatment of hypertension and early stages of diabetic renal dysfunction with antihypertensive agents, and specifically with angiotensin-converting enzyme inhibitors, and laser photocoagulation of proliferative retinopathy and clinically significant macular edema. The latest American Diabetes Association (ADA) guidelines recommend a range of interventions to better improve type 2 diabetes outcomes by controlling the multiple coexisting complications associated with this chronic, progressive disease (Table 1) [13].

\section{Type 1 diabetes}

Type 1 diabetes is a metabolic disorder that results from the progressive destruction of insulin-secreting $\beta$-cells in the islets of Langerhans of the pancreas, leading to insulin insufficiency and hyperglycemia [14]. People with type 1 diabetes are dependent on insulin for the rest of their life. But insulin is not a cure, and people with diabetes are at significant risk for a wide range of serious complications, including heart and kidney diseases and blindness [15].

To avoid the variations in blood glucose levels in those with type 1 diabetes, and to reduce the chance of long-term complications, it would be helpful for new $\beta$-cells to be produced. Ideally, new $\beta$-cells should be derived from cell sources already existing within the person with diabetes so avoiding immunosuppression [16]. Alternatively exogenous sources of surrogate $\beta$-cells have also been described, including adult human pancreases donated after death, fetal pancreas, pluripotent and multipotent stem cells, and cells that reside in the liver. Whilst most of these exogenous sources are heterologous to the recipient; some are autologous such as cord blood stem cells and pluripotent stem cells induced from fibroblasts derived from skin [17].

Transplantation of human pancreatic tissue derived after death is the alternative therapy currently available that allows the possibility of even transient cessation of exogenous insulin.
Table 1 American Diabetes Association-recommended therapeutic goals for patients with type 2 diabetes [13]

\author{
Glycosylated hemoglobin \\ Preprandial plasma glucose \\ Postprandial plasma glucose \\ Blood pressure \\ Low-density lipoprotein cholesterol \\ High-density lipoprotein cholesterol \\ Triglycerides \\ Body mass index
}

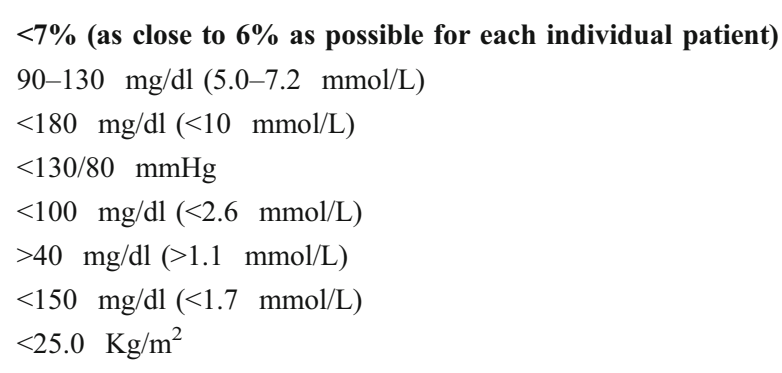




\section{Pancreas transplantation}

There has been a great deal of excitement and investigation in islet transplantation, but at the current time only wholeorgan pancreas transplantation can be counted on for longterm exogenous insulin independence and normalization of $\mathrm{HbA1C}$. The majority of pancreas transplants are simultaneous pancreas-kidney transplantation, the preferred treatment option for diabetics with approaching or coexisting end-stage renal disease [18]. The benefits of pancreas transplantation are clear: improved quality of life, prevention of recurrent diabetic nephropathy, freedom from exogenous insulin with euglycemia and normalization of $\mathrm{HbA1C}$, less stringent dietary restrictions, less frequent blood glucose monitoring and stabilization of or improvement in secondary complications. The major disadvantages to the patient are the operative risk, the need for chronic immunosuppression, and the inherent side effects of chronic immunosuppression [19].

\section{Islet transplantation}

A promising way of treatment of diabetes is using $\beta$-cell replacement therapy. Significant advances in islet isolation techniques have allowed progress in research using transplanted human islets [20].

Enthusiasm for the promise of human islet transplantation started in 2000 with the publication of the Edmonton protocol (Fig. 1). Because many traditional immunosuppression regimens were known to be toxic to islets, Shapiro et al. [21] employed a modified immunosuppression protocol with a monoclonal antibody against interleukin 2, daclizumab, and eliminated glucocorticoids. Notably, both host-versus-graft and autoimmune reactions were avoided. However, despite short term success, long term insulin independence is usually unsustainable. Several follow-up studies indicate that even with the rigorous application of steroid-free immunosuppressive regimens, only $14 \%$ of the patients maintained insulin independence at 2 years, and $30 \%$ had complete graft loss 1 year after the final transplantation [22-24]. It was noteworthy that $80 \%$ of patients evaluated had a "good metabolic outcome," which was defined as decreased insulin requirements and fewer hypoglycemic events 2 years after transplant.

The Edmonton protocol is limited by several major factors: the lack of a sufficiently large source of islets due to the scarcity of cadaveric pancreas donors, and the presence of persistent immune rejection as well as the potential for recurrence of autoimmunity. There is still a slow and progressive loss of insulin production from transplanted islets in diabetic recipients over time, as evidenced by reports that $30-40 \%$ of islet recipients may experience recurrence of autoimmune diabetes with reacquisition of insulin dependence 1 year to 2 years post transplantation [21, 24]. A third limiting factor is islet revascularization, which appears to play an important role in determining the long-term survival and optimal performance of functional islet mass post transplantation. Rapid re-establishment of an appropriate microvascular system in newly transplanted islets is crucial for survival and function of islet grafts. Unfortunately, islets implanted at ectopic sites, such as under the renal capsule or in the liver and spleen, are invariably associated with markedly reduced vascularization, in comparison with native islets in the pancreas $[25,26]$. This impairment in islet revascularization accounts at least in part for the demand of sufficiently large quantities of islet mass for restoration of normoglycemia in type 1 diabetic subjects. In addition, delayed and inadequate islet graft vascularization can deprive islets of oxygen and nutrients, causing islet cells to undergo cellular apoptosis and subsequent cell death, particularly in the core of large islets or in the center of aggregated islet clusters post transplantation. Moreover, a lack of sufficient islet revascularization may also compro-
Fig. 1 The process of islet transplantation (illustration by Giovanni Maki) [32]

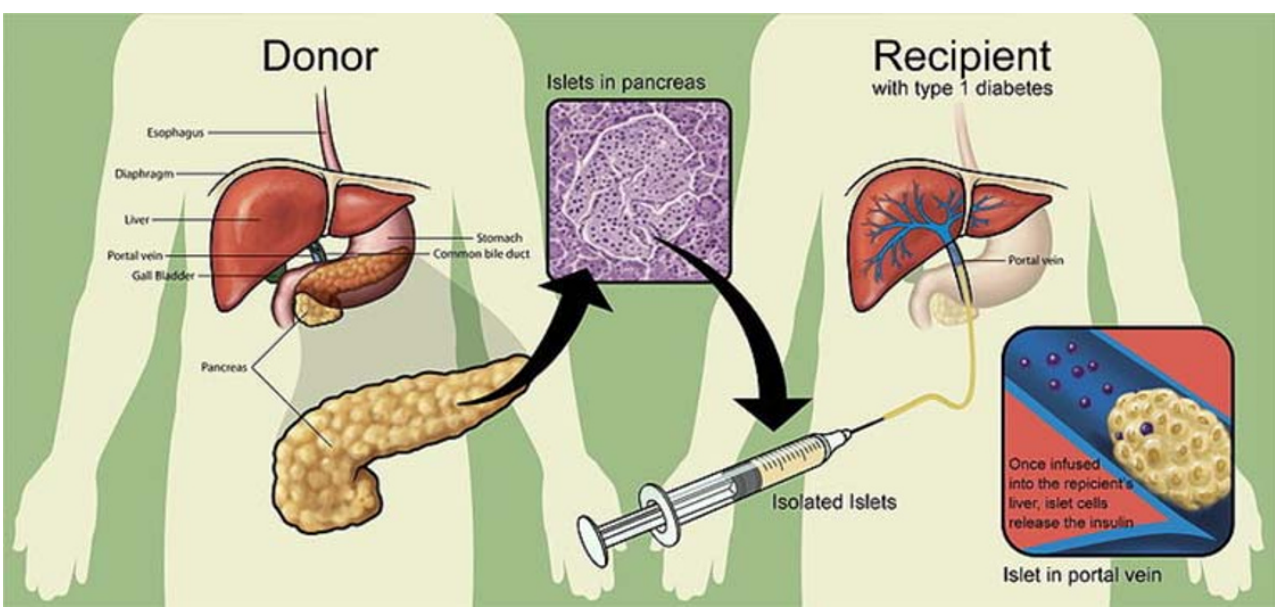


mise the optimal performance of transplanted islets. Indeed, there are clinical data indicating that even after postabsorptive blood glucose homeostasis is restored to normal post islet transplantation, implanted islets do not seem to function at optimal levels, as reflected in their significantly impaired glucose tolerance in diabetic recipients in response to intravenous glucose challenge $[24,27]$. Thus, it is of great significance to define the molecular mechanism of islet revascularization and develop therapeutic angiogenesis approaches to enhance the process of islet revascularization. Such approaches are expected to ensure adequate microvascular perfusion to islet cells and protect implanted islet cells from hypoxia-induced inflammation and necrosis, which will ultimately improve the outcome of islet transplantation by reducing the donor/recipient ratio thus increasing the success rate of islet transplantation [28]. Antioxidant supplementation $[29,68]$, elevation of vascular endothelial growth factor (VEGF) delivery [30] to islet grafts and co-transplantation of bone marrow-derived mesenchymal stem cells [31] improves the outcome of islet transplantation by enhancing islet revascularization.

Many other interventions are being tested to improve islet survival, such as the use of growth factors [62], glucagon-like peptides (GLP) and GLP-1 analogs [63], oxygen carriers [64], substances that reduce inflammatory response [65], anticoagulants [66] and antiapoptotic drugs [67].

The limitations and long term failure of the early transplantation therapies indicate that the procedure in its current format is not suitable for all patients with type 1 diabetes [69]. Intensive research is being conducted to look for alternative sources of $\beta$-cells.

An alternative to avoiding immunosuppression is to deliver encapsulated islets; immobilized in selectively permeable casings, islets would be capable of sensing glucose and secreting insulin but would be protected from immune attack. In theory, these membranes would permit islet transplantation without immunosuppression and would also make xenotransplantation a viable option, potentially solving the problem of donor scarcity by making use of more abundant sources such as porcine islets [33, 34]. Microencapsulation strategies have been used successfully in animal studies; the delivery of bovine islets packaged in alginate gel spheres to the peritoneum of rats has been shown to normalize STZ-induced hyperglycemia [35]. Although complications with vascularization and fibrosis around encapsulated islets have not been totally resolved, clinical trials for encapsulated islet delivery to type 1 diabetics are moving forward [36].

Thus, the development of alternative sources of islets, such as the promotion of transdifferentiation of nonbeta cells into an insulin-secreting phenotype, may be a viable option (Fig. 2). In addition, advances in the understanding of pancreas development have already informed the development of techniques to direct the differentiation of stem cells toward endocrine cells.

\section{Stem cells}

An alternative resource for transplantable $\beta$-cells is the stem cell. Stem cells are cells that are able to proliferate while maintaining an undifferentiated status (self-renewal) and retaining a capacity to differentiate into specialized cell types under appropriate conditions. The sources of such stem cells for the purpose of generating $\beta$-cells were firstly identified through several studies on adult and fetal pancreas. There are two potential sources of stem cells: embryonic stem cells (ES) [47] and the new induced pluripotential stem cells that are reprogrammed from mature adult cells by transduction with transcription factor DNA or recombinant transcription factor proteins [37].

Recently, Kroon et al. [38] reported the development of functional islet-like structures in mice transplanted with human ES cell-derived pancreatic endoderm. Unfortunately, in addition to the generation of functional $\beta$-cells in the vast majority of transplant recipients, Kroon et al. also observed teratoma formation in a small number of cases. This outcome highlights the delicate balance between the risks and benefits that will need to be managed in future stem cell replacement therapies.

New technologies for reprogramming of adult cells to an induced pluripotent state (iPS), similar to ES cells, may change the landscape of future $\beta$-cell therapy [39-43].

Theoretically, it should become straightforward to make autologous iPS cells starting with readily accessible skin or blood cells from any individual, and to use these as a source of transplantable cells, obviating the need for immunosuppression. At a practical level it is not clear that this degree of individualized medicine can be made cost effective for patient populations. However, assessments of cell banking strategies have indicated that as few as ten pluripotent cell lines carefully chosen for homozygosity of the most common alleles at the major histocompatibility genetic loci would provide considerable practical benefit for transplantation matching [44].

It remains to be shown that iPS cells have the same capacity as human ES cells for differentiation toward $\beta$ cells. However, a very recent report documents that human iPS cells, indeed, give rise to insulin-producing cells [45]. The iPS cells were induced to yield pancreatic islet-like clusters using one of the culture protocols previously described for human ES cells.

The recent demonstration that human somatic cells can be reprogrammed to a pluripotent stem cell fate suggests that ethical and legal issues will need to be circumvented $[41,46]$. Two groups of investigators used genes known to be enriched in ES cells and involved in the establishment of 


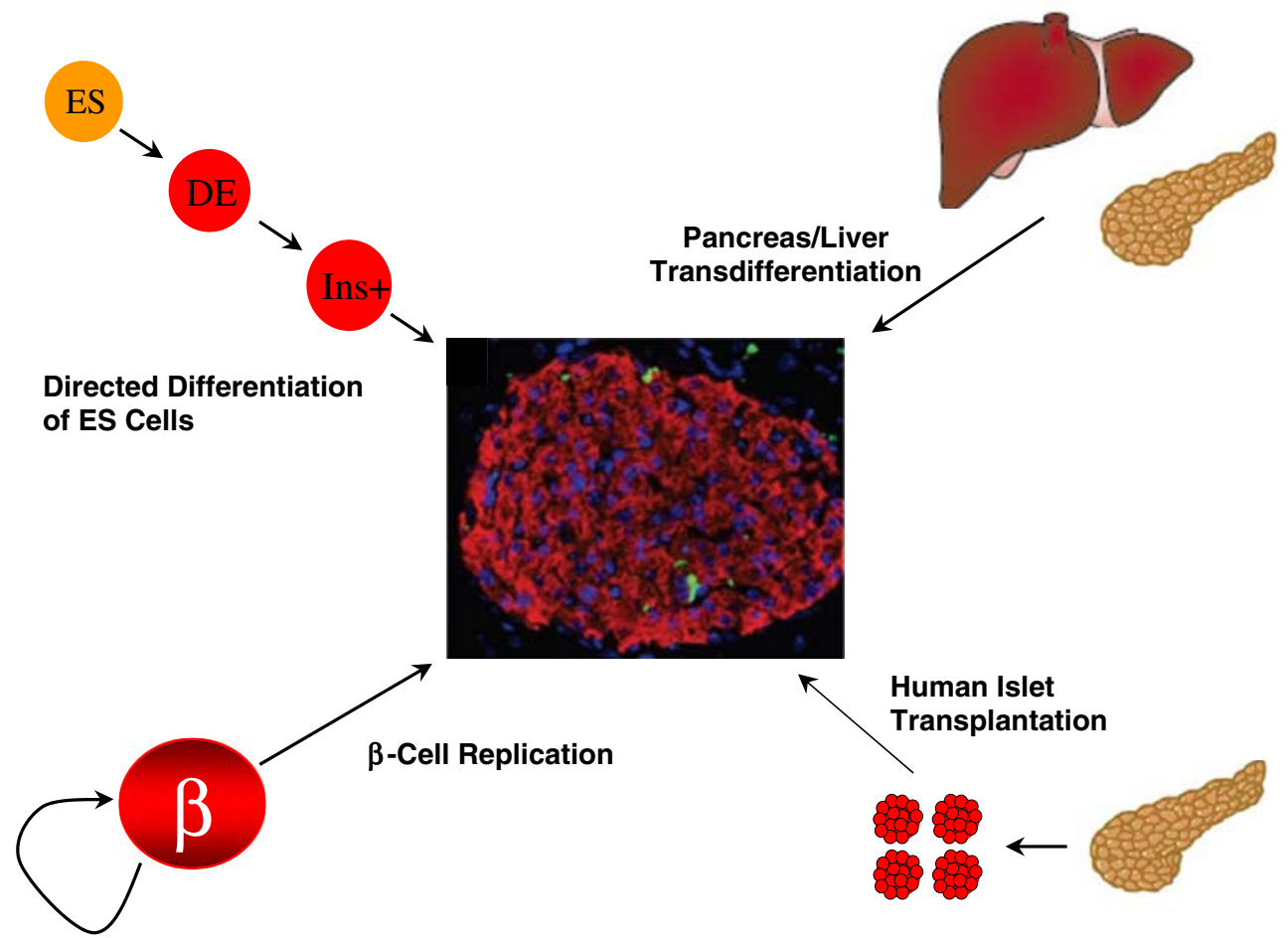

Fig 2 Sources of new $\beta$-cells for the treatment of type 1 diabetes. Type 1 diabetes results from the autoimmune destruction of pancreatic $\beta$-cells. A cure for the disease may lie in the development of techniques to replenish islet mass. Some researchers have already directed the differentiation of ES cells toward an endocrine (Ins+) cell. The potential exists for liver and nonendocrine pancreatic cells to be reprogrammed by gene transfer or growth factor treatments to produce and release insulin in response to glucose. Recent evidence has suggested that adult $\beta$-cells are mitotically active and can replicate in

pluripotency to reprogram human somatic cells. Using slightly different protocols, both groups established pluripotent lines that were capable of differentiating into all three germ layers and forming teratomas when injected into mice. The limitations of this finding are considerable, given that the reprogramming involved the use of viruses and the expression of the proto-oncogene c-Myc. However, alternative methods of cell transduction can be developed and somatic cell-derived insulin-producing cells for diabetes therapy may be possible in the not too distant future.

It is noteworthy that Dr. Nagy and co-workers discovered a new method to create pluripotent stem cells without disrupting healthy genes [48]. This method uses a novel wrapping procedure to deliver specific genes to reprogram cells into stem cells. Previous approaches required the use of viruses to deliver the required genes, a method that carries the risk of damaging the DNA. This new method does not require viruses, and so overcomes a major hurdle for the future of safe, personalized stem cell therapies in humans. This study accelerates stem cell technology and provides a road map for new clinical approaches to devastating diseases such as diabetes. response to increasing insulin demands. A complete understanding of the factors and signals that regulate this process could allow this innate ability to be controlled in patients with diabetes. Finally, cadaveric human islets represent a promising source of therapeutic $\beta$ cells through transplantation. Immunofluorescence staining of a primary adult mouse islet is shown in the center (insulin appears red). Abbreviations: DE, definitive endoderm; ES, embryonic stem; Ins + , insulin-positive

In a 2007 Brazilian study [49], a small number of people newly diagnosed with type 1 diabetes were able to stop using insulin after being treated with stem cells made from their own blood. Although stem cell transplants, which involve shutting down the immune system and then building it up again, can be risky though the technique may 1 day provide an additional treatment option for type 1 diabetes [49, 202].

More recently a pilot study has shown that transfusion of umbilical cord blood in children with type 1 diabetes may decelerate the loss of endogenous insulin production [61]. The experimental challenge in the future will be to unravel the optimal cell source; but there is growing reason for optimism in the replacement of islet transplantation from deceased organ donors by stem cell-derived highly functional $\beta$-cells as an achievable goal.

\section{Transdifferentiation}

Another method of $\beta$-cell replacement for diabetes therapy might involve gene transfer or growth factor treatments to redirect nonislet cells to manufacture 
insulin and respond to changes in extracellular glucose. Given the close embryonic origins of the pancreas and liver, some investigators have focused efforts on transdifferentiation of the liver to a pancreatic endocrine cell fate. Ferber et al. [50]. demonstrated that adenoviralmediated expression of PDX1 induced insulin expression in the liver and rescued STZ-induced hyperglycemia in mice. Although the reprogramming of liver or exocrine tissue to pancreatic endocrine cell fates rescues mouse models of hyperglycemia, the application to human disease may be limited by ongoing autoimmune attack on the $\beta$-cells of patients with type 1 diabetes face [51]. Insulin-producing cells in the liver might also be susceptible to autoimmune lymphocyte infiltration and apoptosis. Offering some optimism in this regard, Shternhall-Ron and co-workers [52] recently demonstrated that adenovirally delivered PDX1 rescued glucose tolerance in cyclophosphamide-accelerated nonobese diabetic mice.

The potential for gene therapy is enormous. For instance, gut $\mathrm{K}$ cells of the mouse were induced to produce human insulin by transfecting the human insulin gene linked to the 5'regulatory region of the gene encoding glucose-dependent insulinotropic polypeptide (GIP) [53]. Also, research demonstrating that hepatocytes transfected with the PDX1 gene under the control of the rat insulin 1 promoter were able to produce insulin $[50,54]$ attracted significant attention and has inspired new hope. In these studies, sufficient levels of insulin were secreted to satisfy the needs of a diabetic mouse, which, when treated, became and remained steadily euglycemic. These studies, however, have not yet been successfully repeated by other groups. This finding suggests that gene therapy-mediated transdifferentiation may prove to be a viable strategy for producing new $\beta$-cells, despite ongoing autoimmune attack (see section IV).

It has recently been shown that infecting liver with a virus containing the gene for neurogenin, a transcription factor that is expressed as cells begin differentiating into insulin-producing $\beta$-cells, cells in the liver can take on the function of pancreatic cells and go on to reverse symptoms of diabetes in a mouse model of the disease [55]. Other researchers showed that adding genes for transcription factors can change cell differentiation [56].

\section{Prevention and early intervention}

In humans, the accumulation of islet antibodies with differential specificities for $\beta$-cell proteins, in combination with genotyping for susceptibility alleles, can predict the risk to develop clinical diabetes. However, researchers are still unable to arrest $\beta$-cell destruction in pre-diabetic patients, even though a lot of evidence collected from preclinical studies using various therapeutic regimens in different animal models for type 1 diabetes has been successful in preventing type 1 diabetes [57]. Some compounds (anti-CD3 antibodies, glutamic acid decarboxylase (GAD) of $65 \mathrm{kDa}$ [GAD65], Diapep277, and antithymocyte globulin) that reestablished long-term tolerance in animal models after new-onset type 1 diabetes show promising effects in reducing $\beta$-cell decline in phase I and II clinical trials in humans with recently diagnosed type 1 diabetes, but none of them was able to cure the disease [58, 60]. Other antigen non-specific agents, such as the antithymocyte globulin and monoclonal anti-CD20 antibody (Rituximab) (http://diabetestrialnet.org), are currently under trial in recent-onset type 1 diabetes [57,60].

The GAD-based diabetes vaccine for type 1 diabetes has been demonstrated to slow or arrest the destruction of insulin producing $\beta$-cells, which is characteristic of autoimmune diabetes. Studies have demonstrated that the Diamyd ${ }^{\circledR}$ vaccine is most efficacious early in the disease process, in recent-onset type 1 diabetes patients. Diamyd Medical is currently conducting two clinical Phase III studies on type 1 diabetes: one in Europe and one in the United States. These studies apply to people diagnosed with type 1 diabetes within the past 3 months. Prevention studies have already been initiated, where researchers intend to evaluate the Diamyd ${ }^{\circledR}$ vaccine in children and adults at risk of developing type 1 diabetes [59]. When people are first diagnosed with type 1 diabetes, they still have cells that produce insulin. Diamyd ${ }^{\circledR}$ treatment is intended to halt or slow the autoimmune destruction process and save the remaining $\beta$-cells. Diamyd can also be combined with other drugs that stimulate the generation of new $\beta$-cells, or with $\beta$-cell transplants.

\section{Type 2 diabetes}

Type 2 diabetes mellitus is a multifactorial metabolic disorder characterized by chronic hyperglycemia due to relative or absolute lack of endogenous insulin. Patients have elevated fasting and postprandial plasma glucose levels. Type 2 diabetes development appears to involve defects in insulin action and secretion [70]. Type 2 diabetes is the result of a combined defect in insulin resistance, $\beta$ cell dysfunction, increased hepatic glucose dysfunction, and reduced glucagon-like peptide 1 (GLP-1) levels [70-72].

Glucose levels remain normal or only mildly impaired when islet $\beta$-cells remain able to compensate with sufficient insulin output to overcome insulin resistance (IR). A progressive decline in $\beta$-cell compensation in a subset of insulin-resistant subjects eventually leads to overt hyperglycemia. IR affects the main insulin target tissues, namely, skeletal muscle, liver, and adipose tissue. The progressive loss of $\beta$-cell function and increased IR may be 
due to a number of factors such as genetic abnormalities and acquired defects. Although a degree of IR may be inherited, it may progress with additional factors such as obesity and a sedentary lifestyle. hyperglycemia can worsen IR and insulin secretion because of effects such as decreased effective responsiveness of $\beta$-cells and decreased sensitization to insulin of target tissues [73].

IR is likely due to the interplay of genetic factors, modifications to the insulin signalling pathway, and inflammation. Insulin secretion is affected by multiple factors, including the baseline secretion capacity, incretin effect, nutrient excess of glucose and free fatty acids (FFAs), and amyloid deposition [73, 74].

Treatment of type 2 diabetes has centered on (1) increasing insulin levels, either by direct insulin administration or oral agents that promote insulin secretion (insulin secretagogues, such as oral sulfonylureas), (2) improving tissue sensitivity, such as with insulin sensitizer biguanide metformin or thiazolidinediones (TZDs), or (3) reducing the rate of carbohydrate absorption from the gastrointestinal tract by the use of $\alpha$-glucosidase inhibitors or agents that decrease gastric motility. Progressive $\beta$-cell dysfunction and $\beta$-cell failure are fundamental pathogenic features of type 2 diabetes, and, ultimately, the development and continued progression of diabetes is a consequence of the failure of the $\beta$-cell to overcome insulin resistance. Current therapies become less effective over time as a result of progressive loss of $\beta$-cell function and number, with the result that a majority of type 2 diabetic patients do not achieve current glycemic goals as reflected by $\mathrm{HbA} 1 \mathrm{c}$ greater than $7 \%$ in more than $60 \%$ of treated patients $[7,8,75-78]$.

\section{Conventional therapies}

Diet and exercise are the first step of therapy for type 2 diabetes; if these do not keep blood sugar at goal levels, then antihyperglycemic agents are added. Drug therapy for type 2 diabetes aims to control blood sugar levels both in the basal (fasting) state and postprandially; rational combinations of agents with different mechanisms of action can be used (Fig. 3).
Fig. 3 Pharmacological treatment of hyperglycemia according to site of action. GLP-1 - glucagon-like peptide 1. DPP 4 -dipeptidyl peptidase 4 . FFAs - free fatty acids. Adapted from Stumvoll et al. 2005 [73]

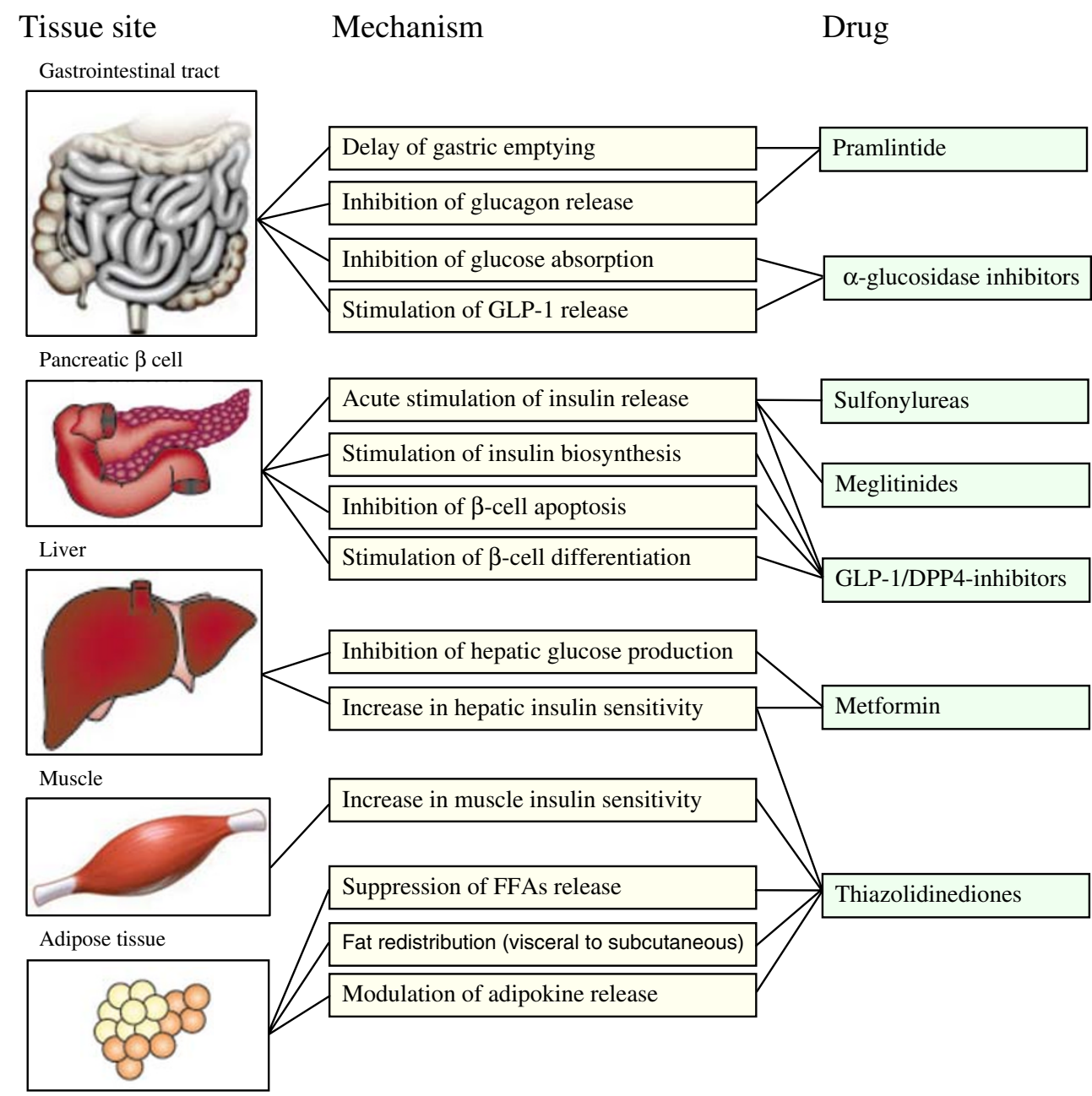


Four major classes of antihyperglycemic agents can be used, either as monotherapy or, more appropriately, in combination with one another:

- Insulin secretogogues

- Insulin sensitizers

- Insulin

- $\alpha$-glucosidase inhibitors

Insulin secretogogues correct hyperglycemia by stimulating insulin secretion-but only if the patient still has enough functioning $\beta$-cells. They close ATP-sensitive potassium channels in the $\beta$-cells of the pancreas, increasing insulin production; slow-acting and rapid-acting agents are available. The major side effects of insulin secretogogues (and insulin replacement) are hypoglycemia and weight gain.

Sulfonylureas are insulin secretagogues, enhancing insulin secretion by binding to a unique receptor on pancreatic $\beta$-cells and having their greatest effect on fasting hyperglycemia $[79,80]$. In this group we can include the second-generation agents gliclazide, glyburide, and glimepiride, as well as the first-generation agents acetohexamide, chlorpropamide, tolazamide, and tolbutamide. When used as monotherapy, sulfonylureas generally result in $\mathrm{HbA} 1 \mathrm{C}$ improvements of a magnitude similar to metformin $(1.5 \%)$ [80]. Sulfonylureas are commonly associated with hypoglycemia and weight gain $(\sim 2 \mathrm{~kg})$. Based on long experience, efficacy, and low cost, sulfonylureas are recommended by the ADA-EASD as options for secondstep pharmacotherapy in patients whose $\mathrm{HbA} 1 \mathrm{C}$ remains elevated on metformin [80].

However, sulfonylureas are also hindered by limited durability of effect, with 3- and 9-year failure rates similar to those described for metformin [76], which is again consistent with progressive $\beta$-cell failure [81]. It has been previously described that gliclazide improves vascular activity decreasing oxidative stress and inflammation. Gliclazide, the main drug used in the ADVANCE study [91], may also be potentially beneficial in abolishing the "metabolic memory".

Meglitinides The recently introduced class of meglitinides consists of nateglinide, which binds to the same site of sulphonylurea receptor 1 as do the sulfonylurea derivatives, and repaglinide, which binds to a nearby site of the receptor, both leading to insulin release. They stimulate rapid, short-lived, insulin secretion [82]. They lower postprandial glucose levels, although fasting hyperglycemia is also improved. Meglitinides are more specific that sulfonylureas and are associated with lower risk of hypoglycemia but clinical experience remains limited. These agents cannot further stimulate insulin release in patients on maximal doses of sulfonylurea derivatives.
These drugs can be used in patients with decreased renal function [83] and for individuals with varying daily meal patterns. Experimental evidence suggests a better preservation of $\beta$-cell function compared to sulfonylureas [84] and improved vascular effects that remain to be clinically proven [85]. The NAVIGATOR (Nateglinide and Valsartan in Impaired Glucose Tolerance Outcomes Research) study aims to assess the utility of these drugs in prevention of diabetes and their impact on cardiovascular morbidity and mortality.

Metformin, is an insulin sensitizer well accepted as a first-line agent for treatment of type 2 diabetes [80]. It is a biguanide derivative that exerts an antihyperglycemic effect with minimal risk of hypoglycemia. Metformin lowers blood glucose concentration and improves insulin sensitivity by reducing hepatic gluconeogenesis and enhancing insulin-stimulated peripheral glucose uptake [79, 80]. In addition, metformin reduces insulin resistance in muscle tissue and the liver, decreasing postprandial hyperglycemia and inhibits adipose tissue lipolysis thereby reducing circulating levels of FFAs [79, 86]. Metformin may also suppress inflammation independently of action on glucose, insulin and FFAs [88]. When used as monotherapy, metformin typically reduces $\mathrm{HbA1C}$ by about $1.5 \%$ [80]. Metformin also improves the lipid profile and lowers blood pressure and plasminogen activator inhibitor- 1 levels in both patients and animals with impaired glucose tolerance and type 2 diabetes [8, 86, 87]. In overweight type 2 diabetic patients, metformin use is associated with decreases in macrovascular morbidity and mortality, effects that appear to be independent of the improvement in glycemic control [8, 86, 92, 93].

Caution must be exercised when using metformin in a number of other patient populations, including those with impaired hepatic function or requiring drug therapy for heart failure, and metformin should be temporarily discontinued prior to surgical procedures or intravascular radiocontrast studies [89]. In addition, metformin has been associated with rare cases of fatal lactic acidosis and is contraindicated in patients with renal dysfunction [89]. Furthermore, a study by Ting et al. noted that metformin use was associated with a risk of vitamin B12 deficiency [90]. The frequency of gastrointestinal adverse events may limit the ability to reach maximally effective doses, with rates of diarrhea and nausea/vomiting of up to $53 \%$ and $26 \%$ of patients, respectively [89]. Because of its efficacy, infrequency of weight gain or hypoglycemia, and low cost, metformin has been recommended by the ADA-EASD as first-line pharmacotherapy for type 2 diabetes [80]. However, the durability of metformin's effectiveness as monotherapy is limited consistent with the progressive loss of $\beta$-cell function seen in type 2 diabetes [81]. 
Thiazolidinediones, another class of insulin sensitizers, currently include pioglitazone and rosiglitazone. They enhance insulin sensitivity reducing hyperglycemia and ameliorating the dyslipidemia and inflammatory milieu of type 2 diabetes [94]. TZDs improve insulin sensitivity in muscle and adipose tissue and in the liver by activating peroxisome proliferators activated receptor $-\gamma$ (PPAR- $\gamma$ ) $[79,80,95]$. TDZs alter adipose metabolism and distribution and redistribution of tissue triglyceride from visceral stores, reducing levels of circulating FFAs apparently by sequestration in a less lipolytic subcutaneous compartment [96]. TDZs also reduce circulating concentrations of proinflammatory cytokines that promote insulin resistance (eg, tumor necrosis factor- $\alpha$ and interleukin 6 ) and at the same time increase concentrations of adiponectin, which has insulin-sensitising and anti-inflammatory properties. TZDs have also been shown to improve $\beta$-cell function, probably as a result of PPAR- $\gamma$-mediated decreases in insulin resistance and $\beta$-cell fatty acid concentrations [95]. TZDs have demonstrated the ability to conserve $\beta$-cell function, delaying or preventing the development of type 2 diabetes in a high-risk population of women with gestational diabetes in the TRIPOD (TRoglitazone In the Prevention Of Diabetes) and PIPOD (Pioglitazone In the Prevention Of Diabetes) studies [97, 98]. A large number of studies show that the TZDs are effective as monotherapy or in combination with metformin, sulfonylureas, and insulin in the treatment of type 2 diabetes. When used as a single agent, TZDs decrease $\mathrm{HbA} 1 \mathrm{C}$ in the range of $1.0-1.6 \%$ and have a lower incidence of treatment failure than with metformin or the sulfonylurea, glyburide [99-101]. However, the TZDs are more effective when used in combination with metformin, sulphonylureas, or insulin [102-104]. The TZDs should not be given to patients with heart failure because they typically cause fluid retention and peripheral edema, worsening heart disease $[105,106]$.

The multiple effects of thiazolidinediones on adipose tissue metabolism and cross-talk of these signals with liver and skeletal muscle, as well as pancreatic $\beta$-cells and the vascular endothelium, might account for the enhancement of insulin action and improvement in insulin secretion with these agents, as well as several beneficial effects on vascular function [107]. Renal and vascular benefits of thiazolidinediones have been demonstrated in controlled studies, for example, showing significant improvement in albumin excretion above that observed with a similar degree of glycemic lowering with sulfonylureas [108].

Unlike metformin, the thiazolidinediones can be used in patients with reduced renal function, and they are better tolerated without significant gastrointestinal side effects. A major adverse effect associated with clinical use of the thiazolidinediones is weight gain, which seems to be coupled to the effects of the drugs on adipose cell differentiation and triglyceride storage. Fluid retention is also linked to the PPAR $\gamma$-agonist activity of the thiazolidinediones, leading to peripheral oedema and a mild hemodilution in some patients $[105,109]$. Fortunately, congestive heart failure is quite rare with use of thiazolidinediones, but remains a serious concern [110]. TZDs may cause hepatotoxicity and should not be used in patients with impaired liver function [111]; the U.S. Food and Drug Administration (FDA) recommends regular liver-function testing in all patients on TZDs. The use of TZDs has also been reported to (1) increase the risk of myocardial infarction and other CV diseases [112, 113], (2) decrease bone formation, accelerate bone loss, and increase the risk of fractures [114, 115], and (3) induce macular edema [116]. The ability of thiazolidinediones to ameliorate risk of atherosclerotic events is being assessed in several large outcomes studies.

TZDs are recommended by the ADA-EASD as an alternative agent in second-step therapy after metformin failure [80]. Although more expensive than generic versions of metformin and sulfonylureas.

\section{$\alpha$-glucosidase inhibitors}

The $\alpha$-glucosidase inhibitors, acarbose, miglitol and voglibose, slow digestion of oligosaccharides, thereby providing an alternative to reduce postprandial glucose levels [117]. The $\alpha$-glucosidase inhibitors do not cause weight gain, can reduce postprandial hyperinsulinemia, and have been shown to lower plasma triglyceride levels in some studies [118]. They must be dosed multiple times per day and are associated with frequent gastrointestinal side effects [80].

They generally have less potent glucose-lowering effects than other oral anti-diabetics [80]. In the STOP-NIDDM (Study to Prevent Non-Insulin Dependent Diabetes Mellitus) trial, acarbose reduced the incidence of new cases of type 2 diabetes in high-risk subjects with impaired glucose tolerance [119]. Acarbose therapy is also associated with a reduction in incidence of cardiovascular events [120] although some controversy is present.

\section{Insulin}

Several different insulin analogs are available for type-1 and advanced type-2 diabetic patients. The injected insulin types differ in their onset and duration. Insulin therapy often has two components, an intermediate acting or longacting insulin given at bedtime, and a rapid-acting insulin given before meals [121].

Insulin administration is the most effective means of restoring glycemic control; because there is no maximum dose, any $\mathrm{HbA} 1 \mathrm{C}$ level can be reduced to the target range if 
insulin is dosed adequately [80]. However, insulin has a number of limitations. It is typically administered by subcutaneous injection, often requiring multiple injections per day. Insulin carries a tangible risk of hypoglycemia, and regular self-monitoring of blood glucose is usually required [80]. It is typically associated with weight gain that significantly increases in patients on intensive insulin therapy [122] with adverse cardiovascular consequences [98]. The ADA-EASD guidelines recommend addition of insulin as a second-step option for patients who are not adequately controlled on metformin monotherapy or as a third-step option for patients who still do not reach the HbA1C target goal on oral combination therapy [80]. Insulin is also the treatment of choice for patients with severely uncontrolled or symptomatic type 2 diabetes [80].

\section{Novel antidiabetic agents}

The currently available therapies used for type 2 diabetes do not significantly improve $\beta$-cell function. In addition, the current approach does not address defects in hormonal secretion thought to play key roles in the pathophysiology of type 2 diabetes.

New emerging therapies for type 2 diabetes have become available in some countries in recent years (Table 2). As a result of their recent availability, long-term studies are lacking and full safety profiles of these compounds are largely unknown, even though they are being used in large numbers of patients.

These drugs offer a range of different mechanisms of action that complement established therapies (Fig. 3). Several of the novel drugs are based on the incretin hormone, GLP-1. GLP-1 controls glucose levels through various mechanisms including glucose-mediated insulin secretion, suppression of inappropriate glucagon release, slowing gastric emptying and increasing satiety [124-126]. The natural hormone is rapidly degraded by the enzyme dipeptidyl peptidase 4 (DPP-4), and the two approaches to new agents are inhibitors of DPP-4 activity and development of GLP-1 analogues resistant to degradation. An important property of these agents is their neutral or beneficial effect on bodyweight [127].

\section{Incretin system}

Gastrointestinal polypeptide hormones that are secreted in response to ingestion of a meal augment postprandial insulin secretion; this is known as the incretin effect and can account for up to $70 \%$ of postprandial insulin secretion [128]. The two most important incretin hormones are GLP-1 and GIP; these hormones are secreted by the L cells of the distal ileum and colon, and the $\mathrm{K}$ cells of the duodenum and upper jejunum, respectively. Circulating concentrations of incretins rise within minutes of eating, implying likely stimulation via activation of neuro-endocrine pathways. Incretins act via specific G-protein-coupled receptors on $\beta$-cells to enhance glucose-stimulated insulin secretion [129].

The incretin effect is almost completely deficient in patients with type 2 diabetes, mainly because of reduced postprandial GLP-1 secretion that is accompanied by a markedly reduced insulinotropic action of GIP [130]. Investigators have observed that infusing GIP or GLP-1 into patients with type 2 diabetes recovers the first phase insulin response, and this indicates an improvement in $\beta$ cell function. In animal models, it has been suggested that GLP-1 stimulates neogenesis of $\beta$-cells and inhibits $\beta$-cell apoptosis. Thus, agents that increase the GLP-1 signal raise the intriguing possibility of replenishing endogenous insulin by increasing the $\beta$-cell population, potentially preventing or even reversing disease progression.

Novel therapies that exploit the incretin effect of GLP-1 include the injectable incretin mimetics and the orally active DPP-4 inhibitors. Their development arose from the understanding and extensive research into incretin physiology and metabolism.

\section{GLP-1 receptor agonists}

The only GLP-1 receptor agonist currently available is exenatide, although a second agent, liraglutide, is in latephase clinical development [133]. These agents are not effective orally and require administration by subcutaneous injection. In clinical trials, they lowered $\mathrm{HbA} 1 \mathrm{C}$ concentration by $0.5-1.0 \%$ and had the additional advantage in producing a significant weight loss. The current indication for these drugs is for use after patients have experienced failure of glycemic control with metformin, sulfonylureas and/or TZDs [125, 131, 132]. Exenatide has been evaluated as an alternative to insulin in patients with type 2 diabetes who have inadequate glycemic control. It leads to weight loss, at least over a 3year period. Long-acting forms of once-weekly injection, such as exenatide LAR, are under development. When used in combination with metformin, sulfonylureas, TZDs, or metformin plus a sulfonylurea, exenatide has been shown to result in weight loss $(0.9-2.8 \mathrm{~kg})$ [134]. Daily liraglutide therapy had similar effects with respect to blood glucose control, $\beta$-cell function, and weight loss as twice-daily exenatide, and its effects were sustained for at least 1 year.

These agents are not generally associated with hypoglycemia but a large proportion of treated patients experience nausea and vomiting, although these gastrointestinal adverse effects tend to become less over time. There have been some recent reports of hemorrhagic or necrotizing pancreatitis and patients should be monitored 


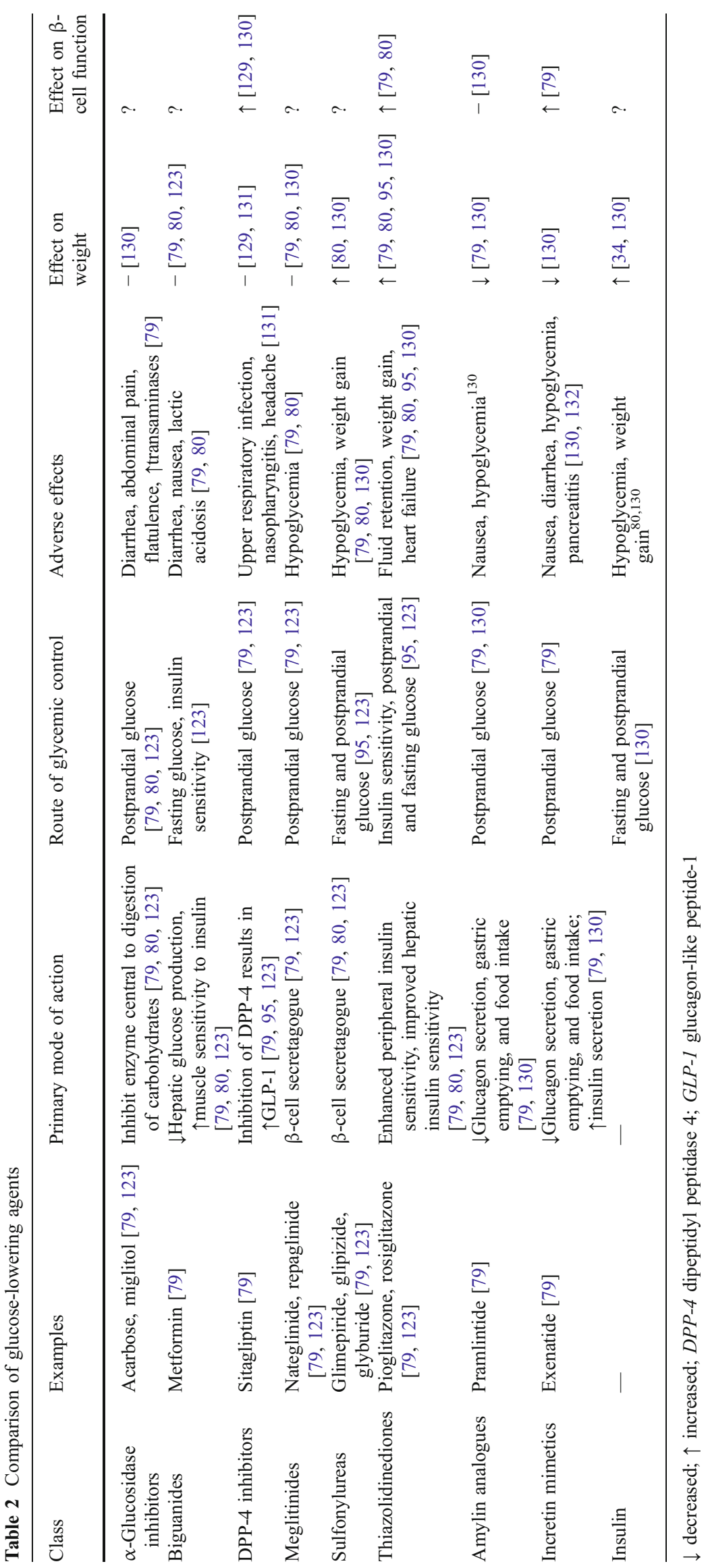


for signs and symptoms [135]. Exenatide is not recommended for patients with severe renal impairment.

\section{Dipeptidyl peptidase 4 inhibitors}

Pharmacological inhibitors of DPP-4 are orally active agents that acutely increase postprandial plasma levels of endogenous GLP-1 typically 2-fold. In contrast with incretin mimetics, and perhaps reflecting the relatively modest increases in incretin levels, DPP-4 inhibitors show little or no evidence of a deceleration in gastric emptying [136], and mild gastrointestinal adverse effects.

There are two DPP-4 inhibitors currently available, which are sitagliptin, available in Europe and the USA, and vildagliptin, currently only available in Europe; both are orally active small molecules that result in increased incretin hormone activity. In clinical trials of these agents, HbA1C concentration was reduced by $0.5-0.9 \%$, and body weight was not significantly altered. They may be used either as monotherapy or in combination with metformin or sulfonylureas. When used as monotherapy, they are generally not associated with hypoglycemia. DPP-4 is found in many tissues throughout the body and there are a large number of potential substrates [194]. As a result, DPP-4 inhibitors can affect many processes that may lead to side effects; for example, they may interfere with the immune system and side effects of upper respiratory tract infections have been reported [194]. While these drugs are being used increasingly and frequently, data on long-term use are lacking and the continued safety profile remains to be established. We do not yet know whether these new agents will have significant, long-term disease-modifying effects.

Sitagliptin is a well tolerated, orally administered inhibitor of DPP-4, the enzyme responsible for rapid degradation of GLP-1 [129, 130, 201]. DPP-4 inhibitors improve glycemic control by increasing levels of biologically intact GLP-1, resulting in a reduction in hepatic glucose output and increase in insulin production. Due to its mechanism of action, it has been suggested that DPP-4 may potentially improve $\beta$-cell function in humans. In addition, these agents appear to be weight neutral when used as monotherapy or in combination with other agents [195].

DPP-4 inhibitors would almost certainly be more useful in type 2 diabetes management if used in addition to agents that would increase incretin secretion (incretinotropics).

Metformin actually increases incretin secretion [196], and this factor probably explains why the addition of DPP-4 inhibitors to metformin therapy has a synergistic effect on reductions in $\mathrm{HbA1C}$ more pronounced than simply adding together the effects of each as a monotherapy: metformin prevents the negative feedback of DPP-4 inhibition on incretin secretion.

\section{Pramlintide}

Amylin (islet amyloid polypeptide) is a 37 -aminoacid peptide hormone that is co-secreted with insulin from islet $\beta$-cells in response to meals [197]. The hormone acts centrally via the area postrema and other regions to activate neural pathways that decrease glucagon release from pancreatic $\alpha$-cells [198] and slow gastric emptying [199], contributing to a glucose-lowering effect. Amylin also appears to act centrally to promote satiety, thereby reducing caloric intake [200]. Human amylin precipitates and aggregates to form amyloid fibres, which play a putative role in the progressive $\beta$-cell destruction [197].

Pramlintide, a human amylin analogue, is currently only approved for use in the USA and as an adjunct to insulin therapy [137, 138]. It is administered by subcutaneous injection before meals and decreases post-meal glucose excursions by slowing gastric emptying and reducing glucagon secretion in a glucose-dependent manner. Clinical trials showed a relatively small reduction in $\mathrm{HbA1C}$ of $0.5-$ $0.7 \%$, although there was also a decrease in body weight of approximately $1-1.5 \mathrm{~kg}$ over 6 months, despite the concomitant treatment with insulin. The weight reduction was most likely caused by the satiety effect.

The $\alpha$-glucosidase inhibitors, pramlintide, and DPP4 inhibitors generally result in smaller reductions in HbA1C when compared with other treatment options recommended by the ADA-EASD $[129,130]$. A comparison of available glucose-lowering agents is presented in Table 3.

Incretin-based therapies give new options for lowering blood glucose and should be placed alongside, and added to, older options. No data are yet available on whether these new agents affect hard endpoints such as cardiovascular disease, morbidity, and mortality.

Although several classes of anti-diabetic drugs are available, achieving and maintaining long-term glycemic control is often challenging, and many current agents have treatment-limiting side effects. So, a significant need for novel therapeutical approaches remains.

\section{Bariatric surgery}

The use of bariatric surgery to achieve and maintain weight loss and ameliorate or resolve diabetes is generating great interest in light of the current epidemic of obesity and diabetes worldwide. Bariatric surgery is recognized as the most effective therapy for treating severe obesity and its associated metabolic abnormalities in patients who have been unsuccessful with dietary, behavioral, and medical interventions. Obesity-related diabetes is controlled by bariatric surgery [145], especially gastric bypass [139] and malabsorptive surgery [140]. However, its use as an 
Table 3 Some experimental drugs in development for the treatment of diabetes

\begin{tabular}{|c|c|c|c|c|}
\hline Company & Drug/Phase & Description: Mechanism of action (MoA) & Advantages & Disadvantages \\
\hline AMLN & Byetta /Phase 3 & $\begin{array}{l}\text { New once-weekly formulation } \\
\text { of GLP-1 receptor agonist }\end{array}$ & $\begin{array}{l}\text { Twice-daily version FDA approved; better } \\
\text { dosing schedule leading to improved } \\
\text { compliance }\end{array}$ & $\begin{array}{l}\text { Potential competition from } \\
\text { Novo Nordisk, } \\
\text { GlaxoSmithKline } \\
\text { and Roche }\end{array}$ \\
\hline XOMA & XOMA-52 /Phase 2 & IL-1 $\beta$ antibody & $\begin{array}{l}\text { Excellent pharmacokinetics; improved } \\
\beta \text {-cell function; monthly injection }\end{array}$ & $\begin{array}{l}\text { Costly, may be difficult to } \\
\text { administer (iv) }\end{array}$ \\
\hline HALO & PH20 /Phase 2 & $\begin{array}{l}\text { Recombinant hyaluronidase } \\
\text { enzyme }\end{array}$ & $\begin{array}{l}\text { Clinically experienced compound; improves } \\
\text { glucose metabolism profile; potential to } \\
\text { reduce hypoglycemia; improves profile } \\
\text { of exogenous glucose }\end{array}$ & More "sticks" by patient \\
\hline VVUS & Qnexa /Phase 3 & $\begin{array}{l}\text { Combination therapy of } \\
\text { phentermine and topiramate }\end{array}$ & $\begin{array}{l}\text { Synergistic combination product treats an } \\
\text { underlying factor of } \mathrm{T} 2 \mathrm{D} \text {, appetite } \\
\text { suppressant }\end{array}$ & $\begin{array}{l}\text { Does not directly control } \\
\text { abnormal glucose profile }\end{array}$ \\
\hline ARNA & Lorcaserin /Phase 3 & $\begin{array}{l}\text { Serotonin } 2 \mathrm{C} \text { receptor agonist in } \\
\text { hypothalamus }\end{array}$ & $\begin{array}{l}\text { Novel mechanism of action for appetite } \\
\text { control; Phase } 3 \text { data showed significant } \\
\text { weight loss }\end{array}$ & $\begin{array}{l}\text { Does not directly control } \\
\text { abnormal glucose profile }\end{array}$ \\
\hline ISIS & $\begin{array}{l}\text { SGLT2 Rx/ } \\
\text { Pre clinical }\end{array}$ & siRNA for SGLT2 & $\begin{array}{l}\text { Novel MoA and molecular target; data } \\
\text { demonstrates reduced expression of SGLT2 } \\
\text { and improved glucose levels in rodents; } \\
\text { experienced in antisense technology }\end{array}$ & $\begin{array}{l}\text { Drug delivery and } \\
\text { pharmacokinetics; limited } \\
\text { clinical data on the } \\
\text { new MoA }\end{array}$ \\
\hline SGMO & SB-509 /Phase 2 & Injectable plasmid encoding ZFP & Novel MoA; severe unmet medical need & $\begin{array}{l}\text { Drug delivery; potential } \\
\text { side effects of } \\
\text { upregulated VEGF }\end{array}$ \\
\hline INCB13739 & $\begin{array}{l}\text { INCB13739 / } \\
\text { Phase } 2 b\end{array}$ & $\begin{array}{l}11 \beta \text {-HSD1 is an enzyme that } \\
\text { converts inactive cortisone } \\
\text { into the potent biologically } \\
\text { active hormone cortisol }\end{array}$ & $\begin{array}{l}\text { Once-daily doses of significantly } \\
\text { improved glycemic control, insulin } \\
\text { sensitivity and total-cholesterol levels. }\end{array}$ & $\begin{array}{l}\text { Some adverse events } \\
\text { occurred in a mild or } \\
\text { moderate intensity; } \\
\text { limited clinical data }\end{array}$ \\
\hline
\end{tabular}

MoA mechanism of action, GLP-1 glucagon-like peptide 1; FDA U.S. Food and Drug Administration; IL $1 \beta$ interleukin-1 $\beta ;$ T2D type 2 diabetes; SGLT2 sodium-dependent glucose cotransporter $2 ; Z F P$ zinc finger protein transcription factor; VEGF vascular endothelial growth factor; $11 \beta$-HSDI $11 \beta$ hydroxysteroid dehydrogenase type 1

intervention for type 2 diabetes is not yet recognized in patients with a BMI below $35 \mathrm{~kg} / \mathrm{m}^{2}$.

The mechanisms by which bariatric surgery achieve improvement of diabetes are not well understood. It is suggested that caloric restriction, weight loss, intestinal malabsorption, hormonal changes in the entero insular axis [141, 145], and rearrangement of the gastrointestinal anatomy are possible features of such mechanisms.

Rubino et al. [142, 146] advocated that the presence of an intestinal feature derived from excessive stimulus of the upper digestive tract would cause deficient incretin action and demonstrated in rats that bypassing a short segment of proximal intestine directly ameliorates type 2 diabetes, independently of effects on food intake, body weight or malabsorption, i.e., the foregut theory. Strader et al. [143], also in a rat model, suggested that lower intestinal stimulation, the hindgut theory, increased synthesis and release of peptide YY and GLP-1 through ileal interposition.

Whether bariatric operations exert an intrinsic antidiabetes action beyond weight loss remains unproven. The best of available evidence indicates that malabsorptive operations presently offer the highest chances of revealing weight independent mechanisms of diabetes resolution, but smart manipulations of the food passage may open entirely new avenues. Laparoscopic interposition of a segment of ileum into the proximal duodenum associated to a sleeve gastrectomy has been recently described as an effective operation in controlling type 2 diabetes in a nonobese population. Associated diseases and related complications were also improved [144].

Blood sugar levels return to normal in 55-95\% of people with diabetes depending on the procedure performed. However, the surgery is expensive and there are risks involved, including a slight risk of death. Additionally, drastic lifestyle changes are required and long-term complications may include nutritional deficiencies and osteoporosis [145].

\section{Experimental drugs in development for the treatment of diabetes}

Many new drugs have entered the market in the past 10 years, and it is controversial that these new drugs are superior to more established therapies [147, 148] probably because many of these drugs are active on the same 
molecular sights as previously approved drugs. Importantly, as the number of patients with diabetes increases, developing new medicines that reduce the cost of long-term treatment for this chronic disease will become a necessity.

The preclinical and clinical data recently presented at the ADA and EASD meetings gives a preview of the new drugs and technologies to come. Many of these drugs are several years away from commercialization. However, because of the new technology, new target or new delivery method, the outlook remains positive for these drugs and companies in the expanding market of diabetes control.

\section{PPAR and GLP-1 receptor agonists}

New technology and approaches for treating type 2 diabetic patients is changing and the competition to secure the growing market is enormous (see Table 3 for a summary). Eli Lilly and Co. and Amylin Pharmaceuticals Inc. (AMLN), makers of Byetta, recently announced a new formulation of this drug that changes the dosing from twice daily to weekly.

Injectable peptide agonists of the GLP-1 receptor have shown significant promise as anti-diabetic agents due to their ability to amplify glucose-dependent insulin release and preserve pancreatic $\beta$-cell mass. BYETTA is the first FDAapproved agent in a class of diabetes therapies called incretin mimetics [135]. Lixisenatide, under development by sanofiaventis, is a novel human GLP-1 receptor agonist for the treatment of type 2 diabetes mellitus. In two phase 2 clinical trials, lixisenatide improved glucose tolerance, resulted in weight loss and lowered HbA1C, thereby causing significantly more patients to achieve target HbA1C levels compared with the placebo. Lixisenatide exhibited wellestablished GLP-1-related gastrointestinal side effects, with mild nausea occurring most frequently; a low frequency of hypoglycemia was also reported. The results of phase 3 trials are awaited for confirmation of the anticipated effects of lixisenatide on glycemic measures and weight [203].

The new GLP-1 analog (VRS-859), created by Versartis, is a recombinant fusion protein. That is, it is made up of exenatide attached to XTEN. XTEN is a tail of an hydrophilic amino acid sequence that covers exenatide, hiding it from DPP-4 and good work for a longer time, permitting less frequent dosing and fewer side effects. A clinical study of VRS-859 in patients with type 2 diabetes is planned for the first half of 2010 .

Peroxisome proliferator-activated receptors (PPARs) are ligand-activated transcription factors, which belong to the nuclear receptor superfamily and which regulate adipogenesis, lipid metabolism, insulin sensitivity, inflammatory processes and blood pressure [149]. Fibrates, long used as triglyceride-lowering agents, are now known to function as activators of PPAR $\alpha$, while the already available thiazolidinediones, rosiglitazone and pioglitazone act via PPAR $\gamma$ to influence free fatty acid flux and reduce insulin resistance and blood glucose levels. Future innovations are expected whereby newer agents will combine PPAR $\alpha$, PPAR $\gamma$ and possibly other PPAR-mediated properties.

Roche recently announced the beginning of a phase 3 clinical investigations for aleglitazar, its innovative PPAR co-agonist R1439 that is uniquely designed to reduce cardiovascular morbidity and mortality in high-risk patients with type 2 diabetes. This decision is supported by data from the Phase II SYNCHRONY study [151]. Aleglitazar is a rationally designed molecule providing balanced dual PPAR $\alpha / \gamma$ activation. Specifically it combines the improvements in peripheral insulin sensitivity (and therefore glycemic control) associated with PPAR $\gamma$ activation, with improved management of dyslipidemia, which is commonly associated with PPAR $\alpha$ activation.

\section{GPR119 agonists}

G protein-coupled receptor 119 (GPR119) is expressed in insulin-producing $\beta$-cells of pancreatic islets together with L-cells of the gastrointestinal tract, and is involved in insulin and incretin hormone release.

Arena Pharmaceuticals has recently reported that stimulation of GPR119 under hyperglycemic conditions leads to a dual nutrient dependent insulinotropic and incretinotropic effect to maintain glucose homeostasis [152-154]. Unlike receptors for GLP-1 and other peptides that mediate enhanced glucose-dependent insulin release, GPR119 has proven amenable to the development of potent, orally active, small-molecule agonists [158].

Specific orally active GPR119 agonists may offer significant promise as novel type 2 anti-diabetics acting in a glucose-dependent fashion. The first GPR119 agonist clinical candidates into Phase I trials (Arena/Ortho McNeil APD597; Metabolex MBX-2982; Prosidion/OSI PSN821) are promising and proof of concept with respect to glycemic control and incretin release [158, 159].

\section{Interleukin-1 $\beta$ inhibitors}

More recently, a new understanding of type 2 diabetes as a disease caused by inflammation as been explored as a source for new therapies $[155,156]$. In type 2 diabetic patients, high glucose concentrations induce the production of interleukin-1 (IL-1) $\beta$ in $\beta$-cells, leading to impaired insulin secretion, decreased $\beta$-cell proliferation, and increased apoptosis. Whereas most type 2 diabetes medicines focus on maximizing insulin production by the pancreas or 
increasing the body's sensitivity to insulin, IL-1 blockers target the inflammatory response that can devastate insulinproducing cells.

It has recently been reported that administration of anakinra (Kineret, a recombinant IL-1-receptor antagonist and a competitive inhibitor of IL-1 binding to type I IL-1 receptors) for 13 weeks to type 2 diabetic patients decreased $\mathrm{HbAlc}$ by $0.46 \%$, increased C-peptide secretion, and decreased the proinsulin/insulin ratio and IL-6 levels, without an effect on body weight or hypoglycemia [155]. Blockade of the master pro-inflammatory signaling protein, IL-1, resulted in disease improvement for type 2 diabetes patients [156].

XOMA-52, is a clinical stage IL- $1 \beta$ antibody for patients with type-2 diabetes. XOMA-52 is unique to other IL-1 $\beta$ inhibitors because of its high affinity and long halflife (22 days). As a result, patients need to be injected with XOMA-52 once monthly and should increase patient compliance. In addition to safety and pharmacokinetic data, the Phase I trial demonstrated decreased $\mathrm{HbA} 1 \mathrm{c}$ levels and improved $\beta$-cell function. XOMA-52 is an attractive drug candidate because it preserves endogenous insulin production in patients with advancing type 2 diabetes. In addition to clinical data, XOMA also presented detail mechanistic rodent and in vitro data on XOMA-52, confirming the results seen in the clinical study [157].

\section{Halozyme}

Co-administration of recombinant human hyaluronidase accelerated the pharmacokinetics and glucodynamics of insulin formulations [160]. For patients with type 1 diabetes, Halozyme (HALO) recently presented Phase 2 data that showed improved pharmacokinetics and glucodynamics with patients receiving Lilly's Humalog and coadministration of Halozyme's PH20 enzyme. PH20 is a recombinant hyaluronidase enzyme that catalyzes the hydrolysis of hyaluronic acid, a major constituent of the interstitial barrier, and increases tissue permeability. This study demonstrated an improved blood glucose metabolism profile in patients taking the combination therapy, reflecting a more physiologic glucose profile thereby likely reducing the amount of exogenous insulin needed along with some potential complications such as hypoglycemia $[160,161]$.

\section{Appetite control}

Anti-obesity drugs facilitate weight loss and contribute to further amelioration of obesity-related health risks such as type 2 diabetes. Several pharmaceutical companies are interested in developing new targets and technologies [162]. VIVUS, Inc. (VVUS) recently presented data from a year- long Phase 2 trial with Qnexa demonstrating reduced $\mathrm{HbA} 1 \mathrm{c}$ levels and helped patients achieve and maintain significant weight loss through appetite suppression. Qnexa is a combination therapy, of low dose phentermine and topiramate, which in combination have synergistic effects through unique molecular targets resulting in reduced appetite and increased satiety - the two main mechanisms that impact eating behaviour. Qnexa, an investigational drug, is being developed to address weight loss. In phase 2 and 3 clinical data to date, Qnexa has demonstrated significant weight loss, glycemic control, and improvement in cardiovascular risk factors.

Arena Pharmaceuticals, Inc. (ARNA) recently described Phase 3 data from its BLOOM (Behavioral modification and Lorcaserin for Overweight and Obesity Management), demonstrating significant weight loss and reduced secondary endpoints associated with cardiovascular disease after 1 year of treatment compared to the placebo. Lorcaserin is a novel serotonin $2 \mathrm{C}$ receptor agonist; selective activation of this Gq-coupled GPCR in the hypothalamus leads to appetite control and increased metabolism [163].

\section{Sodium-dependent glucose cotransporter-2 inhibitors}

The sodium-dependent glucose cotransporter (SGLT) is a molecular target to directly enhance glucose excretion and to safely normalize plasma glucose in the treatment of type 2 diabetes. There are two types of cotransporters: SGLT-1 and SGLT-2. Inhibitors of SGLT-2 block the reabsorption of glucose (in the proximal tubule) from the renal filtrate, whereas the SGLT-1 inhibitors suppress absorption of glucose from the gut; these inhibitors help limit the amount of glucose that is reabsorbed and retained in the body [164 166]. The SGLT inhibitors do not interfere with glucose metabolism, and thus, they are being used complementarily to mainstream approaches to glucose regulation, such as with the PPAR- $\gamma$ agonists, DPP-4 antagonists, and GLP-1 analogues. The majority of inhibitors being developed as antidiabetic agents are selective for SGLT- 2, but there are some inhibitors of SGLT-1 and a mixed type of inhibitors. Most of the SGLT-2 inhibitors, such as dapagliflozin (BMS-512148), remogliflozin, sergliflozin, AVE2268, 189075 , 869682, and T-1095, are derived from the prototype phlorizin and structurally are glycosides. The SGLT-2 inhibitors are also promising for other therapeutic uses such as in obesity because they cause net loss of calories from the body. The SGLT- 2 inhibitors have a low potential for hypoglycemia [166].

Dapagliflozin represents the first selective SGLT2 inhibitor that functions by regulating renal glucose reabsorption. Clinical trial data are limited, but available evidence supports clinically significant reductions in fasting plasma glucose, postprandial plasma glucose, hemoglobin A1c, and body 
weight with this agent [164]. In addition, dapagliflozin has demonstrated excellent tolerability with safety data demonstrated in both Phase 1 and Phase 2 studies. Results of ongoing phase 3 clinical trials are necessary to demonstrate efficacy and safety of this agent across various patient populations and clinical scenarios [167]. Competitive inhibition of SGLT2 therefore represents an innovative therapeutic strategy for the treatment of hyperglycemia and/ or obesity in patients with type 1 or type 2 diabetes by enhancing glucose and energy loss through the urine [166].

Isis Pharmaceuticals, Inc. (ISIS) recently presented preclinical data on ISIS-SGLT2 $2_{\mathrm{Rx}}$ [168], an antisense drug that inhibits the production of SGLT2 that resulted in a significant reduction in blood glucose levels in multiple animal species as well as amelioration of diabetic complications such as cataract formation. ISIS-SGLT $2_{\mathrm{Rx}}$ is the first kidney-targeted antisense drug for type 2 diabetes and Phase 1 study has been initiated. Isis is experienced in RNA targeting drugs and has already commercialized the world's first antisense drug. This novel technology allows Isis to target dysfunctional proteins through decreased transcriptional levels thus modifying signaling pathways not attainable through small molecule inhibition. Antisense technologies may play a key role in finding drugs with unique targets previously unreachable ultimately leading to improved disease management and quality of life.

\section{Regulation of endogenous gene expression using small molecule-controlled engineered zinc-finger protein transcription factors}

Peripheral neuropathy is a common, irreversible complication of diabetes. Currently, the question being addressed is whether or not gene transfer of an engineered zinc finger protein transcription factor (ZFP) designed to upregulate expression of the endogenous VEGF-A gene can protect against experimental diabetic neuropathy (DN) [169-171]. VEGF has protective and regenerative effects on neuronal cells in culture and in animal studies. No regenerative therapies are currently available. Data from an earlier Phase 1, placebo-controlled study using VEGF Zinc Finger Protein Activator (SB-509) in patients with diabetic peripheral neuropathy showed statistically significant improvements in neurological examination and quantitative sensory testing as well as clinically relevant changes in nerve conduction velocity [170].

Thus, Sangamo BioSciences, Inc. (SGMO) recently described the results of phase 2 trials for SB-509 as a treatment for DN resulting in statistically significant and clinically relevant improvements in subjects [171]. DN is a severe physiological consequence of chronic elevated blood glucose levels and is seen in many patients with advanced diabetes. SB-509 is an injectable plasmid encoding a DNAZFP transcription factor designed to upregulate the endogenous expression of the gene encoding VEGF, a peptide responsible for angiogenesis.

\section{$11 \beta$-hydroxysteroid dehydrogenase type 1 inhibitor}

$11 \beta$-hydroxysteroid dehydrogenase type $1(11 \beta$-HSD1) is an enzyme that converts inactive cortisone into the potent biologically active hormone cortisol. This conversion occurs within cells of key metabolic tissues including liver, adipose, muscle and pancreas. Chronically elevated glucocorticoid levels cause obesity, diabetes, heart disease, mood disorders, and memory impairments. Excess $11 \beta$-HSD1 or cortisol leads to insulin resistance and metabolic syndrome in animal models and in humans. Inhibiting $11 \beta$-HSD1 activity signifies a promising therapeutic strategy in the treatment of type 2 diabetes, insulin resistance, obesity, lipid disorders, metabolic syndrome, and other diseases and conditions that are mediated by excessive glucocorticoid action [172]. Cortisol elevates blood glucose levels by driving glucose production in the liver, and inhibiting the uptake and disposal of glucose in muscle and adipose. Thus, cortisol acts as an antagonist of insulin action, and $11 \beta$ HSD1 mediated production of cortisol has been hypothesized to contribute to human insulin resistance, type 2 diabetes, and the often-associated cardiovascular comorbidities.

Results from this double-blind, placebo-controlled Phase IIb trial involving over 300 patients with type 2 diabetes showed that treatment with once-daily doses of INCB13739 significantly improved glycemic control, as measured by HbA1c, insulin sensitivity and total-cholesterol levels in patients with type 2 diabetes [173].

Selectively inhibiting $11 \beta$-HSD1 in humans might become a new and promising approach for lowering blood glucose concentrations and have a favorable effect on insulin resistance, dyslipidemia, and obesity in type 2 diabetes. A large variety of $11 \beta$-HSD1 inhibitor classes have been synthesized [174-176], and some are under investigation by the pharmaceutical industry to treat type 2 diabetes and obesity [177]. The modulation of $11 \beta$-HSD type 1 activity with selective inhibitors has beneficial effects on various conditions including insulin resistance, dyslipidemia, and obesity. A number of $11 \beta$-HSD1 inhibitors (carbenoxolone, AZD4017, BVT116429, PF00915275, PF-915275, PF-877423) are being investigated by many major pharmaceutical companies for treatment of type 2 diabetes and other abnormalities associated with the metabolic syndrome. BVT.2733 reduced food intake but prevented a concomitant reduction in lean body mass and energy expenditure. The latter effects may have contributed to improved glucose tolerance. These compounds improve 
insulin sensitivity in the liver and adipose tissue and possibly may cause weight reduction, as shown in animal studies. They have low potential for hypoglycemia.

\section{FGF-21 for the treatment of type 2 diabetes}

Fibroblast growth factor 21 (FGF-21) is a recently discovered metabolic regulator. FGF-21 activity depends on $\beta$-klotho, a single-pass transmembrane protein. $\beta$-klotho physically interacts with FGF receptors $1 \mathrm{c}$ and 4 . FGF-21 is produced predominatly by the liver that exerts the unique role in the regulation of carbohydrate and lipid metabolism in the liver, adipose tissue and pancreas [178]. FGF-21 stimulates glucose uptake in adipocytes, reduces glucagon secretion and lowers blood glucose and triglyceride levels when administrated to diabetic rodents and monkeys. Its administration in diabetic primates led to a sustainable improvement in glucose control without occurrence of hypoglycemia, a significant improvement of diabetic dyslipidemia and a mild weight loss without any significant side effects [179]. FGF-21 also preserves pancreatic insulin content and $\beta$-cell mass when administered to diabetic mice. Finally, FGF-21 protects animals from diet-induced obesity when overexpressed in transgenic mice [178]. These data indicate that FGF-21 might offer a promising new therapeutic approach to treat type 2 diabetes. All of these characteristics make FGF-21 a hot candidate for the treatment of patients with obesity and type 2 diabetes mellitus.

\section{Antidiabetic effects of glucokinase activators}

Glucokinase (GK) plays a key role in glucose homeostasis by controlling the rate of glucose metabolism in many tissues. GK is believed to function as the primary glucose sensor in a range of neuro/endocrine sentinel cells (including $\beta$-cells) that are involved in glucose homeostasis. In pancreatic $\beta$-cells, GK acts as a sensor for glucose stimulated insulin release and in hepatocytes it catalyzes the first step of glucose metabolism. The relationship between changes in GK activity and fasting plasma glucose in humans with GK diseases has been well established for both loss and gain of function mutations.

Such strong biological rationale for targeting GK as a potential anti diabetic therapy led to the discovery of small molecule allosteric GK activators (GKAs). GKAs bind to an allosteric site $2 \mathrm{~nm}$ away from the bound glucose site and act as non-essential mixed-type enzyme activators [180].

Evidence suggests that the glucose lowering effects in rodents are mediated by dual effects on increasing plasma insulin levels and suppression of hepatic glucose levels as assessed by a pancreatic clamp [181]. Early data in humans recently presented suggests that GKAs offer a promising new therapeutic approach to treat type 2 diabetes [182].

PSN010 is an oral glucokinase activator, being developed for the treatment of type 2 diabetes. By activating the enzyme glucokinase, PSN010 is anticipated to lower blood glucose levels by increasing uptake of glucose in the liver and increasing insulin secretion from the pancreas. PSN010 was discovered and developed in-house through OSI's diabetes and obesity research efforts. The project arising from a research collaboration with the Vanderbilt University Diabetes Center and Tanabe Seiyaku Co. Ltd. PSN010 is currently in Phase I clinical trials. In January 2007, OSI entered into a licensing agreement granting Eli Lilly exclusive rights to its GKA program, which includes PSN010.

\section{Gluconeogenesis inhibitors}

Fasting hyperglycemia in diabetes is well correlated with accelerated hepatic glucose production in type 2 diabetes patients; free fatty acids also induce gluconeogenesis [183]. In animal studies, it has been shown that glucose production in the liver can be inhibited both by substances that act directly on gluconeogenesis and by substances that inhibit fatty-acid oxidation. Therefore, inhibition of both free fatty acid release (such as by SDZ WAG 994) and fatty-acid oxidation (such as by $\beta$-aminobetaine [emeriamine]) in the liver may be efficient modalities of treatment to prevent fasting hyperglycemia in diabetics [182]. Benfluorex, a derivative of fenfluramine, lowers plasma glucose by inhibition of gluconeogenesis [182]. Inhibition of fructose 1, six bisphosphatase, the key hepatic enzyme in gluconeogenesis is also a therapeutic target for treatment of type 2 diabetes [184]. A potent and specific inhibitor of this enzyme [MB06322 (CS017)] may be useful in type 2 diabetes [185].

\section{Oral insulin}

The prospect of a non-injectable means of insulin delivery has always been very attractive. The potential market for an oral form of insulin is assumed to be enormous, thus many laboratories have attempted to devise ways of moving enough intact insulin from the gut to the portal vein to have a measurable effect on blood sugar.

Many biopharmaceutical companies (Apollo Life Sciences, Bicon, Biodel Inc, Oramed Pharmaceuticals Inc) are currently developing their oral insulin products.

Biodel, Inc. is developing an oral formulation of insulin (VIAtab) designed to be administered sublingually. In a Phase I study, VIAtab delivered insulin to the blood stream quickly and resembled the first-phase insulin release spike found in healthy individuals. The company claims that an 
oral insulin therapy would be more convenient than currently available injectable or inhalable therapies, and they expect that convenience to result in increased insulin usage among the currently underserved early-stage patients with type 2 diabetes, thus helping to create better long-term outcomes for that patient population.

Oramed Pharmaceuticals, Inc. is currently conducting Phase $2 b$ clinical trials of its oral insulin capsule, ORMD0801 on 30 patients diagnosed with type 2 diabetes [186]. Oramed's platform technology has two components: 1) A chemical make-up that protects insulin during passage through the gastrointestinal tract, and 2) Absorption enhancers so that insulin could be absorbed by the intestine. Oramed Pharmaceuticals, Inc. in phase 1 clinical trials, has demonstrated that its oral insulin is safe, well tolerated, and has consistently reduced glucose and c-peptide levels in patients [187].

An alkylated, PEGylated, amphiphilic insulin conjugate (HIM-2, Biocon Corp., India) increased oral formulation of insulin in dogs and has reached Phase 2 clinical studies [188]. One of the major challenges in biopharmaceutical development, therefore, continues to be the need for effective oral delivery systems and a number of different approaches have already been used to promote oral delivery of insulin [204].

\section{Insulin mimetics}

The concept of developing insulin mimetics is a long established one, but recent years have seen important developments. For example, protein tyrosine phosphatases (PTPs) are enzymes that control signal transduction pathways, and inhibition of individual PTPs can result in activation of therapeutically relevant kinase cascades. Tyrosine phosphatase 1B (PTP1B) is implicated as a negative regulator of insulin receptor signaling, so smallmolecule inhibitors of this enzyme are being investigated as potential insulin mimetics or insulin augmenting agents. Inhibition of PTP1B in muscle and liver, down-regulates insulin signaling, thereby improving insulin sensitivity [189]. These compounds have a low potential for hypoglycemia. A number of compounds synthesized [190] as well as isolated from various plants have been found to be potent inhibitors of protein tyrosine phosphatase 1B.

During the last decades, a large body of evidence has accumulated to suggest that organo-vanadium compounds exert various insulin-like effects in both in vitro and in vivo systems. These include their ability to improve glucose homeostasis and insulin resistance in animal models of type 1 and type 2 diabetes mellitus. In addition to animal studies, several reports have documented improvements in liver and muscle insulin sensitivity in a limited number of patients with type 2 diabetes [191, 192]. Among these compounds, vanadium (IV) oxo bis(maltolato) was the first to be investigated for its higher potency over inorganic vanadium salts in eliciting insulin-like properties in both in vitro and in vivo systems [193]. There are some concerns about the potential toxicity of available inorganic vanadium salts at higher doses and during long-term therapy. Therefore, new organo-vanadium compounds with higher potency and less toxicity need to be evaluated for their efficacy as potential treatment of human diabetes.

\section{Gene-based therapies for the treatment of diabetes}

An emerging, promising alternative to the traditional treatments of diabetes (injections of insulin and islet transplantation) is the gene-based therapy. Gene therapy, developing rapidly as a result of advanced biotechnologies and the finalized Human Genome Project, is frequently highlighted as one of the most promising technologies of the 21 st century. Although some obstacles remain to be overcome, the risk-benefit balance of gene therapy in diabetes seems to be superior when compared to all other currently used treatment systems.

The transfer of genetic material with therapeutic interest is the aim of gene therapy. This process requires three basic elements: (a) understanding of the pathogenesis of a disease, (b) the targeted genetic sequence, and (c) stable delivery systems providing the targeted tissues with the level and duration of the gene expression necessary to produce the desirable therapeutic effect [205]. Diabetes is an ideal target for gene therapy application, since it provides targets that include suppression of autoimmunity, restoration of insulin responsiveness, functional replacement of pancreatic islets and correction of vascular and nerve damage associated with prolonged hyperglycemia. The cloning of the insulin gene, in the late 1970s, opened up doors for this innovative therapy. In fact, hepatocytes, myocytes, pituitary and exocrine cells have been transformed into insulin-producing substitutive cells [206].

However, even this potent therapeutic approach faces several limitations. Pro-insulin needs to be converted into insulin by specific enzymes termed convertases, which are not expressed in the majority of substitutive cells. Although this can be improved with the aid of alternative enzymes, none of these cells respond to insulin secretagogues by a physiological secretion of insulin. These observations question the capability of gene-therapy constructed nonpancreatic tissues to keep a stringent control over blood glucose concentration as it is provided by functional $\beta$ cells. A more promising approach has been to express pancreatic endocrine developmental factors, such as pancreatic duodenal homeobox-1 (PDX-1), NeuroD and neurogenin-3/betacellulin (Ngn3/Btc), promoting differen- 
tiation of non-endocrine cells in order to reach a $\beta$-cell or islet phenotype, enabling synthesis and secretion of insulin in a glucose-regulated manner [207]. For example, systemic deliver of PDX-1 to the livers of streptozotocin (STZ)treated mice, using a first generation adenovirus gene therapy vector, was shown to induce activation of endogenous pro-insulin 2 gene, leading to increased levels of serum insulin and decreased levels of blood glucose. Notably, despite the transience of the adenoviral constructs, insulin secretion occurred for a period of 4-6 months [54]. An ex vivo approach for transduction of PDX-1 in adult human hepatocytes, have also shown increased expression and secretion of insulin in a glucose-regulated manner, as well as increased expression of somatostatin, glucagon, glucokinase, glucose-transporter 2 (GLUT 2) and several endocrine developmental factors. When transplanted under the renal capsule of diabetic mice, hyperglycemia was ameliorated for prolonged periods of time [209]. Another recent study in a mouse model of diabetic pancreatic damage involving injection of mice with STZ, have shown that transplantation of pancreas with Pdx1-transduced ASCs (adipose tissue-derived stem cells) significantly decreases blood glucose levels and increases cell survival. Moreover, Pdx1-ASCs were shown to be stably engrafted in the pancreas, to acquire a functional $\beta$-cell phenotype and partially restore pancreatic function in vivo [210]. The use of helper-dependent adenoviral (HDAd) system to deliver a combination of NeuroD and Btc genes was also shown to be a promising therapeutic strategy. Indeed, increased expression of these factors lead to marked improvement in fasting hyperglycemia in STZ-treated diabetic mice, restore of the glucose tolerance, as well as, of the serum insulin levels for 3 months [211]. Another good example of a promising therapeutic option is the use of viral vectors carrying Ngn3 and Btc to improve glucose and lipid metabolic abnormalities associated with insulin deficiency. Indeed, experimental studies using STZ-diabetic mice have shown that Ngn3/Btc gene delivery by adenoviral vectors to pancreatic islets restores glucose-stimulated insulin secretion and reverses hyperglycemia in these animals. The treatment also normalizes hepatic glucose secretion and reverses ketonemia. Moreover, this approach was able to restore hepatic glycogen content and hepatic lipogenesis-related gene transcripts back to nondiabetic levels. This study also shows that the neo-islets display electron-dense granules that are similar in appearance to those in pancreatic islets and exhibit a very similar transcription profile on microarray-based transcriptome analysis as compared to pancreatic islets [212].

Improvement of quality life and health condition of diabetic patients may also pass by the direct treatment of diabetic complications, such as neuropathy, renal damage, retinopathy, impaired wound healing and cardiovascular disease. One of the best examples for a possible gene therapy approach is proliferative diabetic retinopathy. This pathology is the leading cause of blindness worldwide and is characterized by retinal neovascularization and increased vascular permeability [213-215]. The eye constitutes a privileged organ to assess the effectiveness of anti-angiogenic therapies, since it is non-invasively available for imaging techniques that allow the study of progression of neovascularization. Vascular endothelial growth factor (VEGF) is considered a central player in the regulation of the pro-angiogenic process, and, therefore, has been proposed as the therapeutic target for treatment of diabetic retinopathy and other chronic diabetic complications related to neovascularization. However, currently used therapeutic approaches targeting VEGF in diabetic retinopathy carry several drawbacks. Some of the approaches developed and clinically tested to reduce neovascularization in diabetic retinopathy include intravitreal injections of antibodies that bind to and block VEGF action and its receptors. Some of these antibodies, such as Ranibizumab (Lucentis) and Bevacizumab (Avastin), were recently approved by the FDA and are commercially available. However, intravitreal administration is associated with increased intraocular hypertension and inflammation, whereas intravenous injection was observed to have significant risks of thromboembolic events. Another disadvantage of these therapeutic approaches is the requirement of frequent and costly injections. Therefore, alternative therapies that silence VEGF levels-by interference RNA (iRNA), for example - are considered as a new generation of more effective strategies [205, 216].

Another good example for the promising use of gene therapy is diabetic critical limb ischemia (CLI). CLI is one of the leading causes of disability among diabetic patients and is the most common cause of non-traumatic amputation in diabetes. It is a disease manifested by diminished blood flow to the legs and appears to be associated, at least in part, with loss of cell and tissue response to ischemia, leading to impairment of the wound healing and angiogenic responses. A recent study using a diabetic model of critical limb ischemia have shown that intramuscular injection of an adenovirus encoding a constitutively active form of HIF-1 $\alpha$ (the key regulator of cell response to low oxygen) into the ischemic limb of diabetic mice increases the recovery of limb perfusion and function, reduces tissue necrosis, rescues the diabetesassociated impairment of circulating angiogenic cells, enhances endothelial nitric oxide synthase activation, and increases vessel density and luminal area in the ischemic limb [217]. Another recent study also shows that local sustained release of VEGF, using adenovirus vector-mediated gene transfer, accelerates experimental diabetic wound healing, by stimulating angiogenesis, epithelialization and collagen deposition. Administration of adenoviral VEGF together with angiopoeitin-1 (Ang-1) has also been shown to be an 
effective and a promising therapeutic approach in the treatment of diabetic myocardial injury after an acute hypoxic challenge, such as a heart attack. Preclinical data demonstrates the efficacy of co-administration of adenoviral VEGF and Ang-1 in increasing angiogenesis, increasing heart collateral development and reducing ventricular remodeling in the infarcted diabetic myocardium [218].

Since obesity is associated with an increased risk of developing insulin resistance and type 2 diabetes, there has been great interest in the development of gene therapies for the control of obesity. Leptin gene therapy is one of the most exciting and promising approaches in this field. This has been achieved by two different systems based on the transfer of the leptin gene to muscles using viral vectors or enhanced electroporation (EP) [219]. Intracerebroventricular injection of recombinant adeno-associated virus encoding leptin in rats consuming a high-fat diet (HFD) have shown that leptin treatment reduces intake and blocks the HFD-induced increase in weight, adiposity and metabolic variables. Blood glucose was shown to be slightly reduced but within the normal range. Treatment with leptin significantly augmented uncoupling protein-1 (UCP1) mRNA expression in brown adipose tissue, indicating increased thermogenic energy expenditure [220]. Through muscle EP, the levels of serum leptin increased by about 200 fold in leptin-treated mice over control mice. Moreover, electrogene transfer resulted in hyperleptinemia, decreased food intake and lower body weight. The production of insulin also decreased, but the blood glucose levels remained normal [221].

Despite all the promising results, there are still several obstacles to overcome. One of them is the nature of the gene delivery system. The ideal gene therapy vector would allow an adequate expression of the transgene for the necessary period of time, it would have the ability to target the disease site and deliver the genetic material in a safe manner. Unfortunately, the currently available gene vectors do not meet all of these requirements. Whereas viral vectors have been proven to be efficient in terms of cell targeting and gene expression, the possibility of host immune response and the random integration of the virus into the host genome raises some doubts about the safety of these vectors [222]. In fact, a widely reported clinical trial in patients with SCID-X1 resulted in T-cell lymphoma after the application of retrovirus gene therapy [223]. On the other hand, nonviral vector systems are more likely to satisfy biosafety concerns, but their transduction efficiency and the lack of cell specificity are still downsides.

\section{Conclusion}

The prevalence of diabetes has been increasing worldwide and is expected to continue to rise over the next 50 years
$[2,224]$. The accompanying increase in the prevalence of diabetes-related complications and the occurrence of diabetes among younger adults, children, and adolescents is likely to have a substantial impact on healthcare costs, with cardiovascular disease and other chronic complications of diabetes accounting for more than one quarter of all direct expenses [3]. Patients with diabetes should be followed closely to ensure that they achieve and maintain both glycemic and nonglycemic treatment objectives. Given the loss of $80 \%$ of $\beta$-cell function at diagnosis of diabetes, as well as the $50 \%$ prevalence of pre-existing coronary heart disease at diagnosis, a more aggressive approach from the earliest stages of disease is clearly indicated [225]. A number of new therapeutic agents have been introduced [75], and a large number of new compounds are in various stages of development for the treatment of type 2 diabetes [208] and this reflects the enormous impact of diabetes on public health. Prevention and major changes in lifestyle factors such as diet and physical exercise will also be needed to contain the growing burden of diabetes.

\section{References}

1. World Health Organisation. Diabetes Fact Sheet $N^{0} 312$. November 2008.

2. Centers for Disease Control and Prevention. Diabetes data and trends. Available via; URL: http://apps.nccd.cdc.gov/DDTSTRS/ default.aspx. Cited 31 October 2009.

3. Cusick M, Meleth AD, Agrón E, et al. Associations of mortality and diabetes complications in patients with type 1 and type 2 diabetes. Diabetes Care. 2005;28:617-25.

4. Mohan V, Pradeepa R. Mortality in diabetes mellitus: revisiting the data from a developing region of the world. Postgrad Med J. 2009;85:225-6.

5. Diabetes Control and Complications Trial Research Group. The effect of intensive diabetes treatment on the development and progression of long-term complications in insulin-dependent diabetes mellitus: the Diabetes Control and Complications Trial. N Engl J Med. 1993;329:978-86.

6. Reichard P, Nilsson B-Y, Rosenqvist U. The effect of long-term intensified insulin treatment on the development of microvascular complications of diabetes mellitus. $N$ Engl J Med. 1993;329:304-9.

7. U.K. Prospective Diabetes Study (UKPDS) Group. Intensive blood glucose control with sulphonylureas or insulin compared with conventional treatment and risk of complication in patients with type 2 diabetes (UKPDS 33). Lancet. 1998;352:837-53.

8. U.K. Prospective Diabetes Study (UKPDS) Group. Effect of intensive blood glucose control with metformin on complication in overweight patients with type 2 diabetes (UKPDS 34). Lancet. 1998;352:854-65.

9. Ohkubo Y, Kishikawa H, Araki E, et al. Intensive insulin therapy prevents the progression of diabetic microvascular complications in Japanese patients with NIDDM: a randomized prospective 6-year study. Diabetes Res Clin Pract. 1995;28:103-17.

10. Selvin E, Marinopoulos S, Berkenblit G, et al. Meta-analysis: glycosylated hemoglobin and cardiovascular disease in diabetes mellitus. Ann Intern Med. 2004;141:421-31. 
11. Rosenstock J, Baron MA, Camisasca RP, et al. Efficacy and tolerability of initial combination therapy with vildagliptin and pioglitazone compared with component monotherapy in patients with type 2 diabetes. Diabetes Obes Metab. 2007;9:175-85.

12. Rosenstock J, Baron MA, Dejager S, et al. Comparison of vildagliptin and rosiglitazone monotherapy in patients with type 2 diabetes: a 24-week, double-blind, randomized trial. Diabetes Care. 2007;30:217-23.

13. American Diabetes Association. Standard of medical care in diabetes. Diabetes Care. 2009;32:S13-61.

14. Atkinson MA. Thirty years of investigating the autoimmune basis for type 1 diabetes. Diabetes. 2005;54:1253-63.

15. Morales A. A better future for children with type 1 diabetes: Review of the conclusions from the Diabetes Control and Complications Trial and the Epidemiology of Diabetes Interventions and Complications study. J Ark Med Soc. 2009;106:903.

16. Furth ME, Atala A. Stem cell sources to treat diabetes. J Cell Biochem. 2009;106:507-11.

17. Couri CE, Voltarelli JC. Autologous stem cell transplantation for early type 1 diabetes mellitus. Autoimmunity. 2008;41:666-72.

18. Wiseman AC. Simultaneous pancreas kidney transplantation: a critical appraisal of the risks and benefits compared with other treatment alternatives. Adv Chronic Kidney Dis. 2009; 16:278-87.

19. Tufveson G. An experience of pancreas and islet transplantation in patients with end stage renal failure due to diabetes type I. Curr Opin Organ Transplant. 2009;14:95-102.

20. Ricordi C, Lacy PE, Finke EH, et al. Automated method for isolation of human pancreatic islets. Diabetes. 1988;37:41320.

21. Shapiro AM, Lakey JR, Ryan EA, et al. Islet transplantation in seven patients with type 1 diabetes mellitus using a glucocorticoid-free immunosuppressive regimen. $\mathrm{N}$ Engl J Med. 2000;343:230-8.

22. Badet L, Benhamou PY, Wojtusciszyn A, et al. Expectations and strategies regarding islet transplantation: metabolic data from the GRAGIL 2 trial. Transplantation. 2007;84:89-96.

23. Shapiro AM, Ricordi C, Hering BJ, et al. International trial of the edmonton protocol for islet transplantation. $\mathrm{N}$ Engl J Med. 2006;355:1318-30

24. Berney T, Toso C. Monitoring of the islet graft. Diabetes Metab. 2006;32:503-12

25. Beger C, Cirulli V, Vajkoczy P, et al. Vascularization of purified pancreatic islet-like cell aggregates (pseudoislets) after syngerneic transplantation. Diabetes. 1998;47:559-65.

26. Mattson G, Jansson L, Carlsson P-O. Decreased vascular density in mouse pancreatic islets after transplantation. Diabetes. 2002;51:1362-6.

27. Ryan EA, Paty BW, Senior PA, et al. Five-year follow up after clinical islet transplantation. Diabetes. 2005;54:2060-9.

28. Mineo D, Pileggi A, Alejandro R, et al. Point: steady progress and current challenges in clinical islet transplantation. Diabetes Care. 2009;32:1563-9.

29. Mohseni Salehi Monfared SS, Larijani B, Abdollahi M. Islets transplantation and antioxidant management: a comprehensive review. World J Gastroenterol. 2009;15:1153-61.

30. Cheng Y, Liu YF, Zhang JL, et al. Elevation of vascular endothelial growth factor production and its effect on revascularization and function of graft islets in diabetic rats. World $\mathrm{J}$ Gastroenterol. 2007;13:2862-6.

31. Figliuzzi M, Cornolti R, Perico N, et al. Bone marrow-derived mesenchymal stem cells improve islet graft function in diabetic rats. Transplant Proc. 2009;41:1797-800.

32. Naftanel MA, Harlan DM. Pancreatic islet transplantation. PLoS Med. 2004;1:e58.
33. Yang Y-G, Sykes M. Xenotransplantation: current status and a perspective on the future. Nat Rev Immunol. 2007;07:519-31.

34. O'Connell PJ. The International Xenotransplantation Association consensus statement on conditions for undertaking clinical trials of porcine islet products in type 1 diabetes-chapter 6: Patient selection for pilot clinical trials of islet xenotransplantation. Xenotransplantation. 2009;16:249-54.

35. Lanza RP, Ecker DM, Kühtreiber WM, et al. Transplantation of islets using microencapsulation: studies in diabetic rodents and dogs. J Mol Med. 1999;77:206-10.

36. Calafiore R, Basta G, Luca G, et al. Standard technical procedures for microencapsulation of human islets for graft into nonimmunosuppressed patients with type 1 diabetes mellitus. Transplant Proc. 2006;38:1156-7.

37. Müller R, Lengerke C. Patient-specific pluripotent stem cells: promises and challenges. Nat Rev Endocrinol. 2009;5:195-203.

38. Kroon E, Martinson LA, Kadoya K, et al. Pancreatic endoderm derived from human embryonic stem cells generates glucoseresponsive insulin-secreting cells in vivo. Nat Biotechnol. 2008;26:443-52.

39. Okita K, Ichisaka T, Yamanaka S. Generation of germlinecompetent induced pluripotent stem cells. Nature. 2007;448:313-7.

40. Park IH, Zhao R, West JA, et al. Reprogramming of human somatic cells to pluripotency with defined factors. Nature. 2007:451:141-6.

41. Takahashi $\mathrm{K}$, Tanabe $\mathrm{K}$, Ohnuki $\mathrm{M}$, et al. Induction of pluripotent stem cells from adult human fibroblasts by defined factors. Cell. 2007;131:861-72.

42. Yu J, Vodyanik MA, Smuga-Otto K, et al. Induced pluripotent stem cell lines derived from human somatic cells. Science. 2007;318:1917-20

43. Wernig M, Meissner A, Foreman R, et al. In vitro reprogramming of fibroblasts into a pluripotent ES-cell-like state. Nature. 2007;448:318-24.

44. Taylor CJ, Bolton EM, Pocock S, et al. Banking on human embryonic stem cells: estimating the number of donor cell lines needed for HLA matching. Lancet. 2005;366:2019-25.

45. Tateishi K, He J, Taranova O, et al. Generation of insulinsecreting islet-like clusters from human skin fibroblasts. J Biol Chem. 2008;283:31601-7.

46. Yu J, Vodyanik MA, Smuga-Otto K, et al. Induced pluripotent stem cell lines derived from human somatic cells. Science. 2007;318:1917-20.

47. Best M, Carroll M, Hanley NA, et al. Embryonic stem cells to beta-cells by understanding pancreas development. Mol Cell Endocrinol. 2008;288:86-94.

48. Woltjen K, Michael IP, Mohseni P, et al. PiggyBac transposition reprograms fibroblasts to induced pluripotent stem cells. Nature. 2009;458:766-77.

49. Voltarelli JC, Couri CE, Stracieri AB, et al. Autologous nonmyeloablative hematopoietic stem cell transplantation in newly diagnosed type 1 diabetes mellitus. JAMA. 2007;297:156876.

50. Ferber S, Halkin A, Cohen $\mathrm{H}$, et al. Pancreatic and duodenal homeobox gene 1 induces expression of insulin genes in liver and ameliorates streptozotocin induced hyperglycemia. Nat Med. 2000;6:568-72.

51. Meier JJ, Bhushan A, Butler AE, et al. Sustained beta cell apoptosis in patients with long-standing type 1 diabetes: indirect evidence for islet regeneration? Diabetologia. 2005;48:2221-8.

52. Shternhall-Ron K, Quintana FJ, Perl S, et al. Ectopic PDX-1 expression in liver ameliorates type 1 diabetes. J Autoimmun. 2007;28:134-42.

53. Cheung AT, Dayanandan B, Lewis JT, et al. Glucose dependent insulin release from genetically engineered $\mathrm{K}$ cells. Science. 2000;290:1959-62. 
54. Ber I, Shternhall K, Perl S, et al. Functional, persistent, and extended liver to pancreas transdifferentiation. J Biol Chem. 2003;278:31950-7.

55. Yechoor V, Liu V, Espiritu C, et al. Neurogenin3 is sufficient for in vivo transdetermination of hepatic progenitor cells into isletlike cells but not transdifferentiation of hepatocytes. Dev Cell. 2009; 16:358-73.

56. Zhou Q, Brown J, Kanarek A, et al. In vivo reprogramming of adult pancreatic exocrine cells to beta-cells. Nature. 2008;455:627-32.

57. Reimann M, Bonifacio E, Solimena M, et al. An update on preventive and regenerative therapies in diabetes mellitus. Pharmacol Ther. 2009;121:317-31.

58. Agardh CD, Cilio CM, Lethagen A, et al. Clinical evidence for the safety of GAD65 immunomodulation in adult-onset autoimmune diabetes. J Diabetes Complications. 2005;19:238-46.

59. Agardh CD, Lynch KF, Palmér M, et al. GAD65 vaccination: 5 years of follow-up in a randomised dose-escalating study in adult-onset autoimmune diabetes. Diabetologia. 2009;52:13638.

60. Bresson D, Matthias von Herrath M. Immunotherapy for the prevention and treatment of type 1 diabetes: optimizing the path from bench to bedside. Diabetes Care. 2009;32:1753-68.

61. Haller MJ, Viener HL, Wasserfall C, et al. Autologous umbilical cord blood infusion for type 1 diabetes. Exp Hematol. 2008;36:710-5.

62. Olsson R, Maxhuni A, Carlsson P. Revascularization of transplanted pancreatic islets following culture with stimulators of angiogenesis. Transplantation. 2006;82:340-7.

63. King $\mathrm{A}$, Lock $\mathrm{J}, \mathrm{Xu} \mathrm{G}$, et al. Islet transplantation outcomes in mice are better with fresh islets and exendin-4 treatment. Diabetologia. 2005;48:2074-9.

64. Avila J, Wang Y, Barbaro B, et al. Improved outcomes in islet isolation and transplantation by the use of a novel hemoglobinbased $\mathrm{O}_{2}$ carrier. Am J Transplant. 2006;6:2861-70.

65. Contreras J, Eckstein C, Smyth C, et al. Activated protein C preserves functional islet mass after intraportal transplantation: a novel link between endothelial cell activation, thrombosis, inflammation, and islet cell death. Diabetes. 2004;53:2804-14.

66. Cabric S, Sanchez J, Lundgren T, et al. Islet surface heparinization prevents the instant blood-mediated inflammatory reaction in islet transplantation. Diabetes. 2007;56:2008-15.

67. Emamaullee J, Stanton L, Schur C, et al. Caspase inhibitor therapy enhances marginal mass islet graft survival and preserves long-term function in islet transplantation. Diabetes. 2007;56:1289-98.

68. Caumo A, Maffi P, Nano R, et al. Transplant estimated function: a simple index to evaluate beta-cell secretion after islet transplantation. Diabetes Care. 2008;31:301-5.

69. Witkowski P, Herold K. Islet transplantation for type 1 diabetes - where should we go? Nat Clin Pract Endocrinol Metab. 2007;3:2-3.

70. DeFronzo RA. The triumvirate: $\beta$-cell, muscle, liver. A collusion responsible for NIDDM. Diabetes. 1988;37:667-87.

71. Ramlo-Halsted BA, Edelman SV. The natural history of type 2 diabetes: practical points to consider in developing prevention and treatment strategies. Clin Diabetes. 2000;18:80-4.

72. Bays H, Mandarino L, DeFronzo RA. Role of the adipocyte, free fatty acids, and ectopic fat in pathogenesis of type 2 diabetes mellitus: peroxisomal proliferator-activated receptor agonists provide a rational therapeutic approach. J Clin Endocrinol Metab. 2004;89:463-78.

73. Stumvoll M, Goldstein BJ, van Haeften TW. Type 2 diabetes: principles of pathogenesis and therapy. Lancet. 2005;365:133346.

74. Petersen KF, Shulman GI. Etiology of insulin resistance. Am J Med. 2006;119:S10-6.
75. Horton ES. Can newer therapies delay the progression of type 2 diabetes mellitus? Endocrine Pract. 2008;14:625-38.

76. Turner RC, Cull CA, Frighi V, et al. Glycemic control with diet, sulfonylurea, metformin, or insulin in patients with type 2 diabetes mellitus: progressive requirement for multiple therapies (UKPDS 49). UK Prospective Diabetes Study (UKPDS) Group. JAMA. 1999;281:2005-12.

77. Saydah SH, Fradkin J, Cowie CC. Poor control of risk factors for vascular disease among adults with previously diagnosed diabetes. JAMA. 2004;291:335-42.

78. Kahn SE, Haffner SM, Heise MA, et al. Glycemic durability of rosiglitazone, metformin, or glyburide monotherapy. N Engl J Med. 2006;355:2427-43.

79. Uwaifo GI, Ratner RE. Differential effects of oral hypoglycemic agents on glucose control and cardiovascular risk. Am J Cardiol. 2007;99:51B-67.

80. Nathan DM, Buse JB, Davidson MB, et al. Medical management of hyperglycemia in type 2 diabetes mellitus: a consensus algorithm for the initiation and adjustment of therapy. A consensus statement from the American Diabetes Association and the European Association for the Study of Diabetes. Diabetologia. 2009;52:17-30.

81. United Kingdom Prospective Diabetes Study Group. Overview of 6 years' therapy of type II diabetes: a progressive disease. Diabetes. 1995;44:1249-58.

82. Black, C., Donnelly, P., McIntyre, L., et al. Meglitinide analogues for type 2 diabetes mellitus. Cochrane. Database Syst. Rev. 2007;2:CD004654. doi: 10.1002/14651858.CD004654. pub2.

83. Hasslacher C. Safety and efficacy of repaglinide in type 2 diabetic patients with and without impaired renal function. Diabetes Care. 2003;26:886-91.

84. Blicklé JF. Meglitinide analogues: a review of clinical data focused on recent trials. Diabetes Metab. 2006;32:113-20.

85. Ceriello A. The post-prandial state and cardiovascular disease: relevance to diabetes mellitus. Diabetes Metab Res Rev. 2000;16:125-32.

86. Kirpichnikov D, McFarlane SI, Sowers JR. Metformin: an update. Ann Intern Med. 2002;137:25-33.

87. Verma S, Bhanot S, McNeill JH. Antihypertensive effects of Metformin in fructose-fed hyperinsulinemic, hypertensive rats. $\mathrm{J}$ Pharmacol Exp Ther. 1994;271:1334-7.

88. Dandona P, Aljada A, Chaudhuri A, et al. The potential influence of inflammation and insulin resistance on the pathogenesis and treatment of atherosclerosis-related complications in type 2 diabetes. J Clin Endocrinol Metab. 2003;88:2422-9.

89. Bristol-Myers Squibb Company. Glucophage (metformin hydrochloride tablets); Glucophage XR (metformin hydrochloride extended-release tablets) available at; $h$ ttp://packageinserts.bms. com/pi/pi_glucophage.pdf.

90. Ting RZ, Szeto CC, Chan MH. Risk factors of vitamin B(12) deficiency in patients receiving metformin. Arch Intern Med. 2006;166:1975-9.

91. The ADVANCE Collaborative Group. Intensive blood glucose control and vascular outcomes in patients with type 2 diabetes. $\mathrm{N}$ Engl J Med. 2008;358:2560-72.

92. Mamputu JC, Wiernsperger NF, Renier G. Antiatherogenic properties of metformin: the experimental evidence. Diabetes Metab. 2003;29:6S71-6.

93. Grant PJ. Beneficial effects of metformin on haemostasis and vascular function in man. Diabetes Metab. 2003;29:6S44-52.

94. Yki-Jarvinen H. Thiazolidinediones. N Engl J Med. 2004;351:110618

95. Ahmed I, Furlong K, Flood J, et al. Dual PPAR $\alpha / \gamma$ agonists: promises and pitfalls in type 2 diabetes. Am J Ther. 2007;14:49 62. 
96. Ye JM, Dzamko N, Cleasby ME, et al. Direct demonstration of lipid sequestration as a mechanism by which rosiglitazone prevents fatty-acid-induced insulin resistance in the rat: comparison with metformin. Diabetologia. 2004;47:1306-13.

97. Buchanan TA, Xiang AH, Peters RK, et al. Preservation of pancreatic $\beta$-cell function and prevention of type 2 diabetes by pharmacological treatment of insulin resistance in high-risk Hispanic women. Diabetes. 2002;51:2796-803.

98. Xiang AH, Peters RK, Kjos SL, et al. Effect of pioglitazone on pancreatic $\beta$-cell function and diabetes risk in Hispanic women with prior gestational diabetes. Diabetes. 2006;55:517-22.

99. Aronoff S, Rosenblatt S, Braithwaite S, et al. Pioglitazone hydrochloride monotherapy improves glycemic control in the treatment of patients with type 2 diabetes: a 6-month randomized placebo-controlled dose-response study. The Pioglitazone 001 Study Group. Diabetes Care. 2000;23:1605-11.

100. Phillips LS, Grunberger G, Miller E, et al. Once- and twice-daily dosing with rosiglitazone improves glycemic control in patients with type 2 diabetes. Rosiglitazone Clinical Trial Study Group. Diabetes Care. 2001;24:308-15.

101. Kahn SE, Haffner SM, Heise MA, et al. Glycemic durability of rosiglitazone, metformin, or glyburide monotherapy. N Engl J Med. 2006;355:2427-43.

102. Stafford JM, Elasy T. Treatment update: thiazolinediones in combination with metformin for the treatment of type 2 diabetes. Vasc Health Risk Manag. 2007;3:503-10.

103. Kipnes MS, Krosnick A, Rendell MS, et al. Pioglitazone hydrochloride in combination with sulfonylurea therapy improves glycemic control in patients with type 2 diabetes mellitus: a randomized, placebo-controlled study. Am J Med. 2001;111:10-7.

104. Raskin P, Randell M, Riddle MC, et al. A randomized trial of rosiglitazone therapy in patients with inadequately controlled insulin-treated type 2 diabetes. Diabetes Care. 2001;24:122632.

105. Waksman JC. Cardiovascular risk of rosiglitazone: another perspective. J Pharm Pharmacol. 2008;60:1573-82.

106. Sarafidis PA, Pantelis A. Thiazolidinedione derivatives in diabetes and cardiovascular disease: an update. Fundam Clin Pharmacol. 2008;22:247-64.

107. Meriden T. Progress with thiazolidinediones in the management of type 2 diabetes mellitus. Clin Ther. 2004;26:177-90.

108. Einhorn D, Aroda VR, Henry RR. Glitazones and the management of insulin resistance: what they do and how might they be used. Endocrinol Metab Clin North Am. 2004;33:595-616.

109. Guan Y, Hao C, Cha DR, et al. Thiazolidinediones expand body fluid volume through PPAR gamma stimulation of EnaC-mediated renal salt absorption. Nat Med. 2005;11:8616

110. Nesto RW, Bell D, Bonow RO, et al. Thiazolidinedione use, fluid retention, and congestive heart failure: a consensus statement from the American Heart Association and American Diabetes Association. Circulation. 2003;108:2941-8.

111. Marcy TR, Britton ML, Blevins SM. Second-generation thiazolinediones and hepatotoxicity. Ann Pharmacother. 2004;38:1419-23

112. Selvin E, Bolen S, Yeh H-C, et al. Cardiovascular outcomes in trials of oral diabetes medications: a systematic review. Arch Intern Med. 2008;168:2070-80.

113. Singh S, Loke YK. The safety of rosiglitazone in the treatment of type 2 diabetes. Expert Opin Drug Saf. 2008;7:579-85.

114. Grey A. Skeletal consequences of thiazolidinedione therapy. Osteoporos Int. 2008;19:129-37.

115. Meier C, Kraenzlin ME, Bodmer M, et al. Use of thiazolidinediones and fracture risk. Arch Intern Med. 2008;168:820-5.
116. Liazos E, Broadbent DM, Beare N, et al. Spontaneous resolution of diabetic macular oedema after discontinuation of thiazolidenediones. Diabet Med. 2008;25:860-2.

117. Scheen AJ. Clinical efficacy of acarbose in diabetes mellitus: a critical review of controlled trials. Diabetes Metab. 1998;24:31120 .

118. Krentz AJ, Bailey CJ. Oral antidiabetic agents: current role in type 2 diabetes mellitus. Drugs. 2005;65:385-411.

119. Chiasson JL, Josse RG, Gomis R, et al. Acarbose for prevention of type 2 diabetes mellitus: the STOP-NIDDM randomised trial. Lancet. 2002;359:2072-7.

120. van de Laar FA, Lucassen PL, Akkermans RP, et al. Alphaglucosidase inhibitors for patients with type 2 diabetes: results from a Cochrane systematic review and meta-analysis. Diabetes Care. 2005;28:154-63.

121. Crasto W, Jarvis J, Khunti K, et al. New insulins and new insulin regimens: a review of their role in improving glycaemic control in patients with diabetes. Postgrad Med J. 2009;85:257-67.

122. Henry RR, Gumbiner B, Ditzler T, et al. Intensive conventional insulin therapy for type II diabetes. Metabolic effects during a 6-mo outpatient trial. Diabetes Care. 1993;16:21-31.

123. American Association of Clinical Endocrinologists. American Association of Clinical Endocrinologists medical guidelines for clinical practice for the management of diabetes mellitus. Endocr Pract. 2007;13:1-68.

124. Drucker DJ. Biologic actions and therapeutic potential of the proglucagon-derived peptides. Nat Clin Pract Endocrinol Metab. 2005;1:22-31.

125. Barnett A. Exenatide. Expert Opin Pharmacother. 2007;8:2593608.

126. Lambeir AM, Durinx C, Scharpé S, et al. Dipeptidyl-peptidase IV from bench to bedside: an update on structural properties, functions, and clinical aspects of the enzyme DPP IV. Crit Rev Clin Lab Sci. 2003;40:209-94.

127. Krentz AJ. Management of type 2 diabetes in the obese patient: current concerns and emerging therapies. Curr Med Res Opin. 2008;24:401-17.

128. Doyle ME, Egan JM. Mechanisms of action of glucagons like peptide 1 in the pancreas. Pharmacol Ther. 2007;113:546-93.

129. Baggio LL, Drucker DJ. Biology of incretins: GLP-1 and GIP. Gastroenterology. 2007;132:2131-57.

130. Holst JJ, Vilsbøll T, Deacon CF. The incretin system and its role in type 2 diabetes mellitus. Mol Cell Endocrinol. 2009;297:12736.

131. Sheffield CA, Kane MP, Busch RS, et al. Safety and efficacy of exenatide in combination with insulin in patients with type 2 diabetes mellitus. Endocr Pract. 2008;14:285-92.

132. Heine RJ, Van Gaal LF, Johns D, et al. Exenatide versus insulin glargine in patients with suboptimally controlled type 2 diabetes: a randomized trial. Ann Intern Med. 2005;143:559-69.

133. Croom KF, McCormack PL. Liraglutide: a review of its use in type 2 diabetes mellitus. Drugs. 2009;69:1985-2004.

134. Kendall DM, Riddle MC, Rosenstock J, et al. Effects of exenatide (exendin-4) on glycemic control over 30 weeks in patients with type 2 diabetes treated with metformin and a sulfonylurea. Diabetes Care. 2005;28:1083-91.

135. U.S. Food and Drug Administration. Information for healthcare professionals: exenatide (marketed as Byetta). Available at: www.fda.gov/cder/drug/InfoSheets/HCP/exenatide2008HCP.htm (accessed October 2009).

136. Ahren B. Dipeptidyl peptidase- 4 inhibitors: clinical data and clinical implications. Diabetes Care. 2007;30:1344-50.

137. Edelman S, Maier H, Wilhelm K. Pramlintide in the treatment of diabetes mellitus. Bio Drugs. 2008;22:375-86.

138. Wysham C, Lush C, Zhang B, et al. Effect of pramlintide as an adjunct to basal insulin on markers of cardiovascular risk in 
patients with type 2 diabetes. Curr Med Res Opin. 2008;24:7985.

139. Knop FK. Resolution of type 2 diabetes following gastric bypass surgery: involvement of gut-derived glucagon and glucagonotropic signalling? Diabetologia. 2009;52:2270-6.

140. Buchwald H. Introduction and current status of bariatric procedures. Surg Obes Relat Dis. 2008;4:S1-6.

141. Ballantyne GH, Gumbs A, Modlin IM. Changes in insulin resistance following bariatric surgery and the adipoinsular axis: role of the adipocytokines, leptin, adiponectin and resistin. Obes Surg. 2005;15:692-9.

142. Rubino F, Marescaux J. Effect of duodenal-jejunal exclusion in a non-obese animal model of T2DM: a new perspective for an old disease. Ann Surg. 2004;239:1-11.

143. Strader AD, Vahl TP, Jandacek RJ, et al. Weight loss through ileal transposition is accompanied by increased ileal hormone secretion and synthesis in rats. Am J Physiol Endocrinol Metab. 2005;288:E447-53.

144. DePaula AL, Macedo ALV, Mota BR, et al. Laparoscopic ileal interposition associated to a diverted sleeve gastrectomy is an effective operation for the treatment of type 2 diabetes mellitus patients with BMI 21-29. Surg Endosc. 2009;23:1313-20.

145. Frachettia KJ, Goldfine AB. Bariatric surgery for diabetes management. Curr Opin Endocrinol Diabetes Obes. 2009;16:119 24.

146. Rubino F. Is type 2 diabetes an operable intestinal disease? A provocative yet reasonable hypothesis. Diabetes Care. 2008;31: S290-6.

147. Henry RR. Evolving concepts of type 2 diabetes management with oral medications: new approaches to an old disease. Curr Med Res Opin. 2008;24:2189-202.

148. Philippe J, Raccah D. Treating type 2 diabetes: how safe are current therapeutic agents? Int J Clin Pract. 2009;63:321-32.

149. Balakumar P, Rose M, Ganti SS, et al. PPAR dual agonists: are they opening Pandora's Box? Pharmacol Res. 2007;56:918.

150. Cleland, J.L., Silverman, J., Schellenberger, V. An extended halflife exenatide construct for weekly administration in the treatment of diabetes mellitus. Proc 69th Scientific Sessions Meeting of the American Diabetes Association, New Orleans p PO (Abstract 1994-PO). 2009.

151. Henry RR, Lincoff AM, Mudaliar S, et al. The dual peroxisome proliferator-activated receptor $\alpha / \gamma$ : results from SYNCHRONY, a phase II, randomised, dose-ranging study in patients with type 2 diabetes. Lancet. 2009;374:126-35.

152. Lan H, Vassileva G, Corona A, et al. GPR119 is required for physiological regulation of glucagon-like peptide-1 secretion but not for metabolic homeostasis. J Endocrinol. 2009;201:21930 .

153. Lauffer LM, Iakoubov R, Brubaker PL. GPR119 is essential for oleoylethanolamide-induced glucagon-like peptide-1 secretion from the intestinal enteroendocrine L-cell. Diabetes. 2009;58:1058 66.

154. Lauffer L, Iakoubov R, Brubaker PL. GPR119: "double-dipping” for better glycemic control. Endocrinology. 2008;149:2035-7.

155. Larsen CM, Faulenbach M, Vaag A, et al. Interleukin-1-receptor antagonist in type 2 diabetes mellitus. $N$ Engl J Med. 2007;356:1517-26.

156. Donath MY, Mandrup-Poulsen T. The use of interleukin-1receptor antagonists in the treatment of diabetes mellitus. Nat Rev Endocrinol. 2008;4:240-1.

157. Donath, M.Y., Weder, C., Brunner, A., et al. XOMA 052, a potential disease modifying anti-IL-1beta antibody, shows sustained HbA1c reductions 3 months after a single injection with no increases in safety parameters in subjects with type 2 diabetes. Proc 69th Scientific Sessions Meeting of the American
Diabetes Association, New Orleans p.OR3 (Abstract 113-OR). 2009.

158. Jones RM, Leonard JN, Buzard DJ, et al. GPR119 agonists for the treatment of type 2 diabetes. Expert Opin Ther Pat. 2009;19:1339-59.

159. Positive results from Metabolex' Phase 1 MBX-2982 clinical trial for treating type 2 diabetes. News-MedicalNet: Oct 14 2009: gpr119.

160. Vaughn DE, Yocum RC, Muchmore DB, et al. Accelerated pharmacokinetics and glucodynamics of prandial insulins injected with recombinant human hyaluronidase. Diabetes Technol Ther. 2009;11:345-52.

161. Hompesch, M., Muchmore, D., Morrow, L., et al. Accelerated insulin pharmacokinetics and improved glycemic control in T1DM patients by coadministration of prandial insulin with recombinant human hyaluronidase. Proc 69th Scientific Sessions Meeting of the American Diabetes Association, New Orleans p.P4 (Abstract 456-P). 2009.

162. Halford JCG, Harrold JA. Neuropharmacology of human appetite expression. Dev Disabil Res Rev. 2008;14:158-64.

163. ClinicalTrials.gov. BLOOM: Behavioral Modification and Lorcaserin for Overweight and Obesity Management. Available via; http://www.clinicaltrials.gov/ct/show/NCT00395135? order=1. Cited 31 October 2009.

164. Cole P, Vicente M, Castaner R. Dapagliflozin: SGLT2 inhibitor antidiabetic agent. Drugs Future. 2008;33:745-51.

165. Jabbour SA, Goldstein BJ. Sodium glucose co-transporter 2 inhibitors: blocking renal tubular reabsorption of glucose to improve glycaemic control in patients with diabetes. Int $\mathrm{J}$ Clin Pract. 2008;62:1279-84.

166. Idris I, Donnelly R. Sodium-glucose co-transporter-2 inhibitors: an emerging new class of oral antidiabetic drug. Diabetes Obes Metab. 2009;11:79-88.

167. Brooks AM, Thacker SM. Dapagliflozin for the treatment of type 2 diabetes. Ann Pharmacother. 2009;43:1286-93.

168. Bhanot, S., Murray, S.F., Booten, S.L., et al. ISIS 388626, an SGLT2 antisense drug, causes robust and sustained glucosuria in multiple species and is safe and well-tolerated. Proc 69th Scientific Sessions Meeting of the American Diabetes Association, New Orleans p.OR (Abstract 328-OR). 2009.

169. Price SA, Dent C, Duran-Jimenez B, et al. Gene transfer of an engineered transcription factor promoting expression of VEGF-A protects against experimental diabetic neuropathy. Diabetes. 2006;55:1847-54.

170. Dent CL, Lau G, Drake EA, et al. Regulation of endogenous gene expression using small molecule-controlled engineered zinc-finger protein transcription factors. Gene Ther. 2007;14:1362-9.

171. Benaim, E., Hamilton, S., Spratt, K., et al. Vascular endothelial growth factor zinc finger protein activator (SB-509) in mild to moderate diabetic peripheral neuropathy patients. Interim Phase 2 Results (SB-509-0601 Study). Proc 69th Scientific Sessions Meeting of the American Diabetes Association, New Orleans p. P8 (Abstract 859-P). 2009.

172. Alberti L, Girola A, Gilardini L, et al. Type 2 diabetes and metabolic syndrome are associated with increased expression of $11 \beta$-hydroxysteroid dehydrogenase 1 in obese subjects. Int $\mathbf{J}$ Obes. 2007;31:1826-31.

173. Rosenstock, J., Banarer, S., Fonseca, V., et al. Efficacy and safety of the 11-beta-HSD1 inhibitor, INCB13739, added to metformin therapy in patients with type 2 diabetes. Proc 69th Scientific Sessions Meeting of the American Diabetes Association, New Orleans 2009 p.LB3 (Abstract 7-LB). 2009.

174. Schuster D, Maurer EM, Laggner C, et al. The discovery of new $11 \beta$-hydroxysteroid dehydrogenase type 1 inhibitors by common feature pharmacophore modelling and virtual screening. J Med Chem. 2006;49:3454-66. 
175. Vicker N, Su X, Ganeshapillai D. Novel non-steroidal inhibitors of human $11 \beta$-hydroxysteroid dehydrogenase type 1 . J Steroid Biochem Mol Biol. 2007;104:123-9.

176. Su X, Vicker N, Trusselle M, et al. Discovery of novel inhibitors of human $11 \beta$-hydroxysteroid dehydrogenase type 1 . Mol Cell Endocrinol. 2009;301:169-73.

177. Hale C, Wang M. Development of 11beta-HSD1 inhibitors for the treatment of type 2 diabetes. Mini Rev Med Chem. 2008;8:702-10.

178. Dostálová I, Haluzíková D, Haluzík M. Fibroblast Growth Factor 21: A novel metabolic regulator with potential therapeutic properties in obesity/type 2 diabetes mellitus. Physiol Res. 2009;58:1-7.

179. Kharitonenkov A, Wroblewski VJ, Koester A, et al. The metabolic state of diabetic monkeys is regulated by fibroblast growth factor-21. Endocrinology. 2007;148:774-81.

180. Leighton B, Atkinson A, Coghlan MP. Small molecule glucokinase activators as novel anti-diabetic agents. Biochem Soc Transact. 2005;33:371-4.

181. Matschinsky FM. Assessing the potential of glucokinase activators in diabetes therapy. Nat Rev Drug Discov. 2009;8:399-416.

182. Kaal MJH, Collet JT. Inhibition of gluconeogenesis An option for the treatment of type 2 diabetes mellitus? Pharmaceut Week. 1993;128:507-11.

183. Edgerton DS, Johnson KM, Cherrington AD. Current strategies for the inhibition of hepatic glucose production in type 2 diabetes. Front Biosci. 2009;14:1169-81.

184. van Poelje PD, Dang Q, Erion MD. Fructose-1, 6-bisphosphatase as a therapeutic target for type 2 diabetes. Drug Discov Today. 2007:4:103-9.

185. Erion MD, van Poelje PD, Dang Q. MB06322 (CS-917): a potent and selective inhibitor of fructose 1, 6-bisphosphatase for controlling gluconeogenesis in type 2 diabetes. Proc Nat Acad Sci USA. 2005;102:7970-5.

186. Arbit E, Kidron M. Oral insulin: the rationale for this approach and current developments. J Diabetes Sci Technol. 2009;3:5627.

187. "Apollo's oral insulin—2007 R\&D update and 2008 roadmap" (pdf). Apollo Life Sciences. 2007-12-20. http://www.apollolifesciences. com/Uploads/ASX/ASX 109.pdf. Retrieved 2008-02-04.

188. Clement S, Dandona P, Still JG, et al. Oral modified insulin (HIM2) in patients with type 1 diabetes mellitus: results from a phase I/II clinical trial. Metabolism. 2004;53:54-8.

189. Johnson TO, Ermolieff J, Jirousek MR. Protein tyrosine phosphatase 1B inhibitors for diabetes. Nat Rev Drug Discov. 2002;1:696-709.

190. Pei Z, Liu G, Lubben TH, et al. Inhibition of protein tyrosine phosphatase $1 \mathrm{~B}$ as a potential treatment of diabetes and obesity. Curr Pharm Des. 2004;10:3481-504.

191. Mehdi MZ, Pandey SK, Théberge JF, et al. Insulin signal mimicry as a mechanism for the insulin-like effects of vanadium. Cell Biochem Biophys. 2006;44:73-81.

192. Srivastava AK, Mehdi MZ. Insulino-mimetic and anti-diabetic effects of vanadium compounds. Diabet Med. 2005;22:2-13.

193. Vardatsikos G, Mehdi MZ, Srivastava AK. Bis(maltolato)oxovanadium (IV)-induced phosphorylation of PKB, GSK-3 and FOXO1 contributes to its glucoregulatory responses. Int $\mathbf{J}$ Mol Med. 2009;24:303-9.

194. Lambeir AM, Durinx C, Scharpé S, et al. Dipeptidyl-peptidase IV from bench to bedside: an update on structural properties, functions, and clinical aspects of the enzyme DPP IV. Crit Rev Clin Lab Sci. 2003;40:209-94.

195. Barnett A. DPP-4 inhibitors and their potential role in the management of type 2 diabetes. Int J Clin Pract. 2006;60:145470 .
196. Chia CW, Egan JM. Incretin-based therapies in type 2 diabetes mellitus. J Clin Endocrinol Metab. 2008;93:3703-16.

197. Pittner RA, Albrandt K, Beaumont K, et al. Molecular physiology of amylin. J Cell Biochem. 1994;55:19-28.

198. Fineman M, Weyer C, Maggs DG, et al. The human amylin analog, pramlintide, reduces postprandial hyperglucagonemia in patients with type 2 diabetes mellitus. Horm Metab Res. 2002;34:504-8.

199. Young A. Inhibition of gastric emptying. Adv Pharmacol. 2005;52:99-121.

200. Chapman I, Parker B, Doran S, et al. Effect of pramlintide on satiety and food intake in obese subjects and subjects with type 2 diabetes. Diabetologia. 2005;48:838-48.

201. Lyseng-Williamson KA. Sitagliptin. Drugs. 2007;67:587-97.

202. Couri CE, Oliveira MC, Stracieri AB. C-peptide levels and insulin independence following autologous non myeloablative hematopoietic stem cell transplantation in newly diagnosed type 1 diabetes mellitus. JAMA. 2009;301:1573-9.

203. Christensen M, Knop FK, Holst JJ, et al. Lixisenatide, a novel GLP-1 receptor agonist for the treatment of type 2 diabetes mellitus. IDrugs. 2009;12:503-13.

204. Maher S, Leonard TW, Jacobsen J, et al. Safety and efficacy of sodium caprate in promoting oral drug absorption: from in vitro to the clinic. Adv Drug Deliv Rev. 2009;61:1427-49.

205. Zaia JA. The status of gene vectors for the treatment of diabetes. Cell Biochem Biophys. 2007;48:183-90.

206. Levine F, Leibowitz G. Towards gene therapy of diabetes mellitus. Mol Med Today. 1999;5:165-71.

207. Samson SL, Chan L. Gene therapy for diabetes: reinventing the islet. Trends Endocrinol Metab. 2006;17:92-100.

208. Hughes TE. Emerging therapies for metabolic diseases - the focus is on diabetes and obesity. Curr Opin Chem Biol. 2009;13:332-7.

209. Sapir T, Shternhall K, Meivar-Levy I, et al. Cell-replacement therapy for diabetes: generating functional insulin-producing tissue from adult human liver cells. Proc Natl Acad Sci U S A. 2005;102:7964-9.

210. Kajiyama, H., Hamazaki, T.S., Tokuhara, M., et al. Pdx1transfected adipose tissue-derived stem cells differentiate into insulin-producing cells in vivo and reduce hyperglycemia in diabetic mice. Int. J. Dev. Biol. 2009. doi: 10.1387/ ijdb.092953hk.

211. Kojima H, Fujimiya M, Matsumura K, et al. NeuroD-betacellulin gene therapy induces islet neogenesis in the liver and reverses diabetes in mice. Nat Med. 2003;9:596-603.

212. Yechoor V, Liu V, Paul A, et al. Gene therapy with neurogenin 3 and betacellulin reverses major metabolic problems in insulin-deficient diabetic mice. Endocrinology. 2009; 150:4863-73.

213. Cunha-Vaz JG. Pathophysiology of diabetic retinopathy. Br J Ophthalmol. 1978;62:351-5.

214. Engerman RL. Pathogenesis of diabetic retinopathy. Diabetes. 1989;38:1203-6.

215. Stratton IM, Adler AI, Neil HA, et al. Association of glycaemia with macrovascular and microvascular complications of type 2 diabetes (UKPDS 35): prospective observational study. BMJ. 2000;321:405-12.

216. Campochiaro PA. Potential applications for RNAi to probe pathogenesis and develop new treatments for ocular disorders. Gene Ther. 2006;13:559-62.

217. Sarkar K, Fox-Talbot K, Steenbergen C, et al. Adenoviral transfer of HIF-1 \{alpha\} enhances vascular responses to critical limb ischemia in diabetic mice. Proc Natl Acad Sci U S A. 2009;106:18769-74.

218. Samuel SM, Akita Y, Paul D, et al. Co-administration of adenoviral VEGF and ang-1 enhances vascularization and 
reduces ventricular remodeling in the infarcted myocardium of type i diabetic rats. Diabetes. 2010;59:51-60.

219. Prud'homme GJ, Draghia-Akli R, Wang Q. Plasmid-based gene therapy of diabetes mellitus. Gene Ther. 2007;14:553-64.

220. Dube MG, Beretta E, Dhillon $\mathrm{H}$, et al. Central leptin gene therapy blocks high-fat diet-induced weight gain, hyperleptinemia, and hyperinsulinemia: increase in serum ghrelin levels. Diabetes. 2002;51:1729-36.

221. Prud'homme GJ, Glinka Y, Khan AS, Draghia-Akli R. Electroporation-enhanced nonviral gene transfer for the prevention or treatment of immunological, endocrine and neoplastic diseases. Curr Gene Ther. 2006;6:243-73.
222. Xu R, Li H, Tse LY, et al. Diabetes gene therapy: potential and challenges. Curr Gene Ther. 2003;3:65-82.

223. Hacein-Bey-Abina S, Von Kalle C, Schmidt M, et al. LMO2associated clonal $\mathrm{T}$ cell proliferation in two patients after gene therapy for SCID-X1. Science. 2003;302:415-9.

224. Wild S, Roglic G, Green A, et al. Global prevalence of diabetes: estimates for the year 2000 and projections for 2030. Diabetes Care. 2004;27:1047-53.

225. Gastaldelli A, Ferrannini E, Miyazaki Y, et al. Beta-cell dysfunction and glucose intolerance: results from the San Antonio metabolism (SAM) study. Diabetologia. 2004;47:319. 